\title{
A mathematical model for green supply chain coordination with substitutable products
}

\author{
Zahra Basiri, Jafar Heydari* \\ School of Industrial Engineering, College of Engineering, University of Tehran \\ * Corresponding Author, E-mail: J.Heydari@ut.ac.ir
}

\begin{abstract}
This paper investigates the green channel coordination issue within a two-stage supply chain (SC). The investigated SC sells a non-green traditional product and also plans for releasing a new substitutable green product beside the current traditional product. Demand for both products is a function of the retail price as well as products' green quality and retailer's sales efforts. Both retail price and sales effort level for the green product are decided by the retailer while the product green quality is the manufacturer's decision variable. Three decision scenarios are modelled and compared: (1) decentralized scenario where each member decides independently based on own profit, (2) integrated scenario where there is a one decision maker in the system, and (3) collaborative scenario that aims to enhance the overall channel profit subject to Pareto improvement for each member. Closed-form expressions of optimal retail price, sales effort and green quality are derived for the first two scenarios, and a mathematical programming model is developed for the collaborative scenario. Our numerical investigations revealed that the proposed collaboration model is capable of enhancing the SC profit fairly close to the centralized model and also ensures higher profits for both channel members than the decentralized decision making.
\end{abstract}

Key words: Green supply chain coordination; Substitutable products; Consumer environmental awareness; Environmental quality; Sales efforts; Collaborative decision making;

\section{Introduction}

In the past years, the rapid economic growth and increasing consumers' overuse have affected the ecosystems globally (Chen \& Chai, 2010). Climate changes, global warming, ozone layer hole, rise of sea levels, pollution of noise, air and waters, acidic rains and soil erosions all are symptoms of environmental degradation (Ramlogan, 1997). The environmental degradation would worsen if the current trend of irresponsible economic growth pattern continues (Ishaswini \& Datta, 2011). On the other hand, the environmental issues have attracted the public attention in last decades. Raising public environmental concerns about harmful activities have influenced the supply chain planning and operations significantly. As a result, the reduction of environmental harms became an important issue in the modern supply chains to gain a significant competitive advantage and better public image for the supply chain (Govindan et al., 2014a). Besides, the 
environmental issues added more complexities to the competitive business environments, i.e. in addition to economical profits of channels, there are some environmental goals too. Carbon emission reduction, reverse supply chains, product life cycle considerations, and producing green products, all are samples of the environmental efforts by modern supply chains around the world.

There is plenty of evidence showing that environmental issues are a major concern for both governments as well as industries (Govindan, et al., 2014b). International organizations and national governments have set up greenhouse gases (GHGs) emission reduction targets for the next 10- 50 years. For instance, the EU plans for a 20\% reduction by 2020 and the UK based its Climate-Change Act schedules for an $80 \%$ reduction by 2050 . The UK retailers such as Asda, Tesco, M\&S, and Debenhams take some actions to reduce their carbon footprint in all their operations, including raw material supply, production and logistics. Wal-Mart and Tesco have the leverage to insist that their suppliers reduce carbon emission levels in production and transportation (Ramanathan et al., 2012).

Meanwhile, in the recent years, there is a broad public attention to environmental issues. The U.S. Environmental Protection Agency (EPA) encourages customers to purchase ecofriendly products and provides an online carbon footprint calculator for everyone. Some eco-labels are introduced to guide consumers toward green buying (Teisl et al., 2002; Du et al., 2016). With the increase of environmental concerns among customers and their environmental awareness, they become more cautious on their purchase. Environmentally aware people tend to buy eco-friendly products with higher environmental quality than the usual ones even in more costs. On the other hand, different kind of sales efforts such as advertising for green products and eco-marketing make people more aware of green buying and its impact on the environment.

All mentioned above, as motivations for this study, are reasons that emphasized on the importance of entering green products to shopping centres and also the significance of consumer environmental awareness (CEA) in nowadays businesses. In this paper, we extend classic channel optimization models to include both green and traditional products together. In this context, this paper aims to provide a decision model to achieve both environmental as well as commercial goals for supply chains. We know that the environmental goals of channels should be in equilibrium with the economic goals to ensure a profitable business (Gosh \& Shah, 2012; Jaber, et al., 2013; Zhang, et al., 2014).

This study extends the scope of SC coordination to the environmental decisions. Main objective of SC coordination models is to enhance the channel members' decisions to optimize the total SC profit. Usually the most previous attempts in this field focused on economic goals even those studies that focused on green topics often investigated the closed-loop channels, reverse channels, product life cycle and amount of greenhouse gas emissions while with the increase of public awareness on environmental issues and green sales efforts, they became important parameters for a green supply chain. 
In this study, we investigate the following research questions: (1) How does the market demand changes in presence of the green product in addition to the traditional one? (2) How does the consumer environmental awareness as an effective parameter and product green quality as an adjustable decision variable impact the channel coordination? (3) What are the optimal values of sales efforts, green quality and retail price in order to maximize supply chain profit while both channel members are better off than the decentralized decision making?

To answer the research questions, in this study an analytical model of a two-stage SC is developed. The investigated SC sells one type of non-green traditional product and plans to add a substitutable green-type of product along with the current conventional product. Production and selling biodegradable paper cups versus Styrofoam cups is a well-known example of such substitutable products. Demand for both types of products is a function of the retail price as well as products' green quality and retailer sales efforts. While retail price and green quality of the conventional product are predetermined and fixed, the problem is to set these values for new-released green product in order to maximize the SC gain from selling both products in the market. Retail price and sales effort level for green product are decided by the retailer while the product green quality is the manufacturer's decision variable. Three decision scenarios are analysed and compared: (1) decentralized decision making scenario, (2) integrated (centralized) scenario, and (3) collaborative decision making scenario in which objective function is set to maximize the whole system profit subject to Pareto-efficient solutions for both SC members. Our results reveal that the proposed collaboration model is capable of achieving Pareto-efficient solution on pricing, green-quality, and sales effort decisions for the green product while none of the channel members are worse-off.

This paper contributes to the literature of sustainable operations management by developing a new collaboration mechanism in which both downstream and upstream can effectively contribute to enhance the SC efficiency in planning for releasing a new green product along with a non-green traditional product. The proposed collaboration model can find a win-win solution for both members in deciding about their decision variables without need for a supplementary coordination contract. Researches in the area of green supply chain coordination are in early stages and to the best of the authors' knowledge none of the previous works did not use the methodology similar to the current paper for treating the green SC coordination problem. This paper is also contributes on practice by advising managers how to plan efficiently to release a green type of a product beside the original non-green one. Sometimes releasing such a product is assumed to making loss as it can steal market share of the original product. The proposed model reveals that collaboration of SC members in such situations not only can enhance total demand but also increases both downstream and upstream profitability.

This paper is organized as follows. Section 2 provides a brief review of relevant literature. Section 3 introduces the investigated supply chain and basic assumptions. In Section 4 
model formulations and solutions are presented in three scenarios: (1) decentralized, (2) integrated scenario (3) collaboration scenario. Section 5 provides numerical experiments and sensitivity analyses. Finally, Section 6 discusses about conclusions and future research directions.

\section{Literature Review}

This study is related to the issue of green channel coordination in presence of environmentally aware consumers. More precisely, this study is associated with the SC models with two substitutable products. Some papers in the conventional non-green environments which consider the sales-effort and/or quality dependent demand are also technically related to the current proposed models. In this section, we briefly survey the recent literature of this area.

Some previous studies assumed demand as a function of both price and sales effort. Ma et al. (2013b) studied different channel structures via game theory approach in a two-stage SC to find the amount of players' decision variables where demand is a function of retailer's sales effort and product quality. In another study, Ma et al. (2013a) investigated an SC channel and showed that both a two-part tariff contract alone, and in combination with a cost-sharing contract cannot coordinate the channel appropriately. Although their models were examined in a non-green context, their assumed demand function has some similarities with the current study. Wu (2013) analyzed two competitive supply chains where demand is a function of retail price and sales efforts and coordinated the channels by Nash's bargaining model. Zhao et al. (2014) using a game theory approach under fuzzy demand that is dependent on both retail price and sales effort showed that in both conditions of symmetric and asymmetric information, the coordinated channel creates better solutions than the traditional one. De Giovanni (2014) extended the concept of sales effort to green sales effort by proposing a closed-loop SC in which the retailer invests in green advertising. In the investigated closed-loop SC by De Giovanni (2014), the retailer by green advertising aims to increase demand and at the same time raise the consumers' willingness to return their obsolete products.

Effect of consumer environmental awareness (CEA) on increasing demand of green products is another research stream, which is related to the current work. With the rise of CEA, it is expected to increase pleasure of consuming a product for which an environmentfriendly substitute is available (Conrad, 2005). By the increase of public knowledge about environmental issues, the market purchase behavior is changed; peoples prefer to buy green product instead of usual ones but do not pay too more money (Ishaswini \& Datta, 2011). Green advertising is one of the best-known methods to increase CEA and change the people living style to a green life (Haytko \& Maulich, 2011; Abd Rahim et al., 2012).

Using a game theory approach in a hybrid-product (traditional and green product) supply chain when demand is a function of CEA, Liu et al. (2012) proposed a channel coordination model to reach the equilibrium condition. In another study, a two-part tariff contract was 
used to coordinate a channel in which the demand is a function of price, environmental quality, and CEA (Gosh \& Shah, 2012). Zhang \& Liu (2013) showed that suitable channel coordination can be achieved under a Stackelberg game by applying a revenue sharing contract. Xia and He (2014) analyzed a two-echelon supply chain with deterministic product demand, and it has been proved that sharing the carbon emission reduction costs is an effective encouragement for the manufacturer to reduce its carbon emission. They proposed a new side payment self-executing contract to achieve Pareto-efficient solutions. Gosh \& Shah (2015) proposed a cost-sharing contract to initiate the manufacturer to improve the greening level of product, but the proposed mechanism was not capable of reach the centralized model. Li et al., (2016) investigated a competitive dual channel green supply chain in which the market demand is a deterministic function of product price and greenness level. They applied a two-part tariff contract under a Stackelberg game approach to coordinate the channel. Recently, Zhang et al. (2015) applied a return policy in a twostage SC with two substitutable products (traditional and green product) where the demand is a function of price and green quality. In their model, CEA as the coefficient of green quality in the demand function is assumed to be a stochastic variable.

Table 1. Comparison of previous models with the current study

\begin{tabular}{|c|c|c|c|c|c|c|c|c|c|c|}
\hline \multirow[t]{2}{*}{ Authors } & \multirow[t]{2}{*}{ Contract } & \multicolumn{3}{|c|}{$\begin{array}{c}\text { Demand } \\
\text { pattern }\end{array}$} & \multicolumn{4}{|c|}{ Decision variables } & \multirow[t]{2}{*}{$\begin{array}{c}\text { Green issues } \\
\text { focus }\end{array}$} & \multirow[t]{2}{*}{$\begin{array}{c}\text { Channel } \\
\text { coordinatior }\end{array}$} \\
\hline & & 吾 & 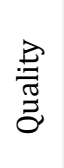 & 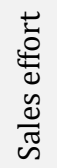 & 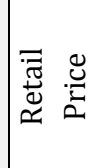 & $\stackrel{\vec{\Xi}}{\stackrel{\pi}{\Xi}}$ & 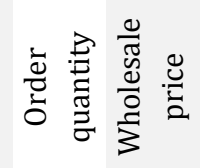 & 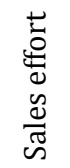 & & \\
\hline \multicolumn{11}{|c|}{ Part A: Single product channels (Green and non-green SCs) } \\
\hline Liu et al, (2012) & Game theory & $\checkmark$ & $\checkmark$ & & $\checkmark$ & $\checkmark$ & $\checkmark$ & & $\checkmark$ & - \\
\hline Ghosh \& Shah (2012) & Two part tariff & $\checkmark$ & $\checkmark$ & & $\checkmark$ & $\checkmark$ & $\checkmark$ & & $\checkmark$ & $\checkmark$ \\
\hline Ma et al. (2013a) & $\begin{array}{l}\text { Two-part tariff } \\
\text { plus quality effort } \\
\text { cost sharing }\end{array}$ & $\checkmark$ & $\checkmark$ & $\checkmark$ & $\checkmark$ & $\checkmark$ & $\checkmark$ & $\checkmark$ & & $\checkmark$ \\
\hline Ma et al. (2013b) & Game theory & $\checkmark$ & $\checkmark$ & $\checkmark$ & $\checkmark$ & $\checkmark$ & $\checkmark$ & $\checkmark$ & & $\checkmark$ \\
\hline Wu (2013) & Nash bargaining & $\checkmark$ & & $\checkmark$ & $\checkmark$ & & $\checkmark$ & $\checkmark$ & & $\checkmark$ \\
\hline Zhao et al. (2013) & Game theory & $\checkmark$ & & $\checkmark$ & $\checkmark$ & & $\checkmark$ & $\checkmark$ & & - \\
\hline De Giovanni (2014) & Differential game & $\checkmark$ & $\checkmark$ & $\checkmark$ & & $\checkmark$ & $\checkmark$ & $\checkmark$ & $\begin{array}{c}\text { Closed Loop } \\
\text { SC }\end{array}$ & - \\
\hline Xia \& He (2014) & $\begin{array}{l}\text { Cost sharing plus } \\
\text { side payment }\end{array}$ & $\checkmark$ & & & & & & & $\checkmark$ & $\checkmark$ \\
\hline Ghosh \& Shah (2015) & Cost sharing & $\checkmark$ & $\checkmark$ & & $\checkmark$ & $\checkmark$ & $\checkmark$ & & $\checkmark$ & - \\
\hline \multicolumn{11}{|c|}{ Part B: Two product channels (Green SCs) } \\
\hline
\end{tabular}




\begin{tabular}{ccccccccccccc}
\hline Zhang et al. (2015) & Return policy & $\checkmark$ & $\checkmark$ & & & $\checkmark$ & $\checkmark$ & & & $\checkmark$ & & $\checkmark$ \\
This paper & $\begin{array}{c}\text { Collaboration } \\
\text { model }\end{array}$ & $\checkmark$ & $\checkmark$ & $\checkmark$ & $\checkmark$ & $\checkmark$ & & & $\checkmark$ & & $\checkmark$ & \\
\hline
\end{tabular}

Most related studies are presented in Table 1. Although some of these studies concentrated on channel coordination issue using supply chain contracts considering CEA and downstream sales efforts, some of them were not able to coordinate the channel and also all of them did not consider the green issues and importance of green sales efforts in a hybrid product channel. In the current study, the demand function of both products (traditional and green products) depends on the product green quality, retailer's sales efforts and retail price, simultaneously. In addition, in this study a novel collaboration model based on the mathematical programming approach is proposed, which is capable of achieving solutions fairly close to centralized solution and at the same time guarantees Pareto-improvement situation for both channel members.

\section{Supply chain model}

This study analyses a two-stage supply chain (single manufacturer and single retailer). In the original state, SC sells only one type of non-green traditional product, but plans to add the green-type of product to the market. The functionality of these two products is the same, and therefore, they are substitutable, e.g. a biodegradable paper cup versus a Styrofoam cup. Thus, the manufacturer produces two substitutable products one green type and other non-green traditional type. Non-green traditional product is a longestablished product in the market and therefore, its green quality and retail price are predetermined and fixed. The problem of the investigated SC is to set retail price, green quality level, and green sales effort level for the new-launched green product such that the overall SC profitability from selling both types of products is maximized. Retail price and sales efforts level for the green product are the decision variables under the authority of the retailer. The environmental quality level of the green product is the manufacturer's decision variable. The demand function of each product type is expressed as:

$$
\begin{aligned}
& D_{1}=a-b p_{1}+\tau e_{1}+\gamma s_{1}+\theta\left(p_{2}-p_{1}\right)-\theta_{e}\left(e_{2}-e_{1}\right)-\theta_{s}\left(s_{2}-s_{1}\right) \\
& D_{2}=a-b p_{2}+\tau e_{2}+\gamma s_{2}+\theta\left(p_{1}-p_{2}\right)-\theta_{e}\left(e_{1}-e_{2}\right)-\theta_{s}\left(s_{1}-s_{2}\right)
\end{aligned}
$$

where, index " 1 " denotes the green product, and index " 2 " refers to the non-green traditional product. By rewriting demand for the green product, we have $D_{1}=a-(b+$ $\theta) p_{1}+\left(\tau+\theta_{e}\right) e_{1}+\left(\gamma+\theta_{s}\right) s_{1}+\theta p_{2}-\theta_{e} e_{2}-\theta_{s} s_{2}$. Coefficients of $p_{1}, e_{1}$, and $s_{1}$ in demand function $D_{1}$ is greater than coefficients of $p_{2}, e_{2}$, and $s_{2}$ which implies that demand of green 
product is more sensitive to its own specifications (price, green quality, and sales effort) rather than the non-green product specifications. The same conclusion can be derived for the non-green product demand function. The assumed demand functions are general enough for our case and do not violate known and accepted assumptions in this area of research. At the same time, the proposed demand functions do not impose unrealistic assumptions in our model compared to similar previous papers.

The total channel demand for both product types is equal to:

$D=D_{1}+D_{2}=2 a-b\left(p_{1}+p_{2}\right)+\tau\left(e_{1}+e_{2}\right)+\gamma\left(s_{1}+s_{2}\right)$

where, $a$ is the primary market potential for each product type, $p$ is the retail price which affects demand proportionate to price elasticity coefficient $b$; $\tau$ is the consumer environmental awareness (CEA) level, which represents the tendency of customers to buy a product with higher green quality $e$; the retailer's sales efforts level is denoted as $s$ which affects demand proportionate to sales effort elasticity coefficient $\gamma$. Parameters $\theta, \theta_{e}$, and $\theta_{s}$ are defined as the sensitivity of switchovers toward price difference, green quality difference, and sales effort difference of two products, respectively. It is assumed that the retailer does not make efforts for selling traditional product; i.e. $s_{2}=0$. In addition, it is assumed that both channel members know all the model parameters. Similar types of demand functions are also assumed by previous studies (e.g. Tsay \& Agrawal, 2000; Liu et al. 2012; Ma et al., 2013a; Gosh \& Shah, 2015). Since we considered substitutable products, the coefficients $b, \tau, \gamma$, and $\theta$, which are about the sensitivity of customers on product's specifications (i.e. price, green quality, sales effort level), are assumed identical for both product types. Previous models with substitutable products have also supposed the same condition (e.g. Hsieh and Wu 2009; Zhao et al. 2012a; Zhao et al. 2012b; Zhao et al. 2014; Krommyda et al. 2015; Zhang et al. 2015). In addition, we assumed when both product types are the same specifications, then the market is equally divided between them. In other words, an identical primary market potential $a$ for both product types is assumed.

The manufacturer by spending more can enhance the green quality level of the green product. The greening cost imposed to the manufacturer for providing a product with green quality $e$ is given by $\frac{h e^{2}}{2}$, where $h$ is the greening investment coefficient. Such a cost function is used repeatedly in the literature (e.g. Chen 2001; Liu et al. 2012; Gosh \& Shah 2012; Gosh \& Shah 2015; Zhang et al. 2015). On the other hand, the retailer is also capable of making sales efforts for enhancing the demand for the green product. The retailer's cost to make sales efforts level $s$ is given by $\frac{k s^{2}}{2}$, where $k$ is the sales efforts coefficient. Such a quadratic-type function is frequently used by previous researchers (e.g. De Giovanni, 2011; Lau et al. 2012; Ma et al. 2013a, b; Wu 2013; Zhao \& Wei 2014; Gao et al. 2016). Also we take $\theta_{e}=\theta \tau$ and $\theta_{s}=\theta \gamma$ similar to some earlier models (e.g. Liu et al., 2012; Zhang et al., 2015). 


\section{Model parameters:}

$i \quad$ Index of product type; i=1, 2 for green and traditional product, respectively

$c_{i} \quad$ Manufacturer's production cost per unit of product $i$

$h \quad$ Greening cost coefficient

$k \quad$ Sales-effort investment coefficient

$\tau$ Consumer environmental awareness (CEA) level

$\gamma \quad$ Sales-effort elasticity coefficient of demand

a Primary market potential for green/traditional product

$b \quad$ Price elasticity coefficient of demand

$\theta \quad$ Switchover coefficient toward green/traditional price difference

$\theta_{e} \quad$ Switchover coefficient toward green/traditional environmental quality difference

$\theta_{s} \quad$ Switchover coefficient toward green/traditional sales effort level difference

$w_{i} \quad$ The unit wholesale price of product $i$

$\Pi_{s c} \quad$ Channel profit

$\Pi_{m} \quad$ Manufacturer's profit

$\Pi_{r} \quad$ Retailer's profit

\section{Decision variables:}

$p_{1}$ The unit retail price of green product (retailer's decision variable); $p_{1} \in \mathrm{R}^{+}$

$e_{1} \quad$ The environmental quality of green product (manufacturer's decision variable); $e_{1} \in \mathrm{R}^{+}$

$s_{1} \quad$ Retailer's green sales effort level for green product (retailer's decision variable); $s_{1} \in \mathrm{R}^{+}$

Superscripts ' $t$ ', ' $i$ ', and ' $c o$ ' stand for decentralized, integrated, and collaboration scenarios. In addition, asterisk denotes the optimal value for a decision variable or a profit function. The investigated supply chain is formulated under three different scenarios: (1) decentralized scenario, (2) integrated scenario, (3) Collaborative decision making scenario. The optimal solutions are derived in all three scenarios.

\section{Decision making structures}

In this section, channel members' profit functions are formulated and optimal decisions on $p_{1}, s_{1}$ and $e_{1}$ in each scenario are derived. Concavity of profit functions is proved, and closed-form relations for decision variables are extracted in both decentralized and integrated scenarios. Finally, collaboration scenario is developed as a mathematical programming model to ensure a win-win situation for both members while the objective is maximizing the total channel profit. 


\subsection{Decentralized scenario}

Under the decentralized scenario, each channel member aims to maximize own profit regardless of the other member. As a result, the retailer according to own profit function decides on the retail price and level of green sales effort while the manufacturer decides on the environmental quality of green product. Under the decentralized scenario, the retailer moves first and decides on $p_{1}$ and $s_{1}$ while it is assumed that the retailer is aware of the manufacturer's decision $e_{1}$.

The manufacturer's profit function is formulated as:

$$
\begin{aligned}
& \Pi_{m}=\left(w_{1}-c_{1}\right)\left(\begin{array}{c}
a-b p_{1}+\tau e_{1}+\gamma s_{1} \\
+\theta\left(p_{2}-p_{1}\right)-\theta_{e}\left(e_{2}-e_{1}\right)+\theta_{s} s_{1}
\end{array}\right) \\
&+\left(w_{2}-c_{2}\right)\left(\begin{array}{c}
a-b p_{2}+\tau e_{2}+\theta\left(p_{1}-p_{2}\right) \\
-\theta_{e}\left(e_{1}-e_{2}\right)-\theta_{s} s_{1}
\end{array}\right)-\frac{h e_{1}^{2}}{2}
\end{aligned}
$$

Theorem 1. Under the decentralized scenario, the manufacturer's profit function $\Pi_{m}$ is concave in $e_{1}$ and there is a unique optimal value for $e_{1}^{t *}$ that maximizes $\Pi_{m}$ as:

$$
e_{1}^{t *}=\frac{\left(\mathrm{w}_{1}-\mathrm{c}_{1}\right)\left(\tau+\theta_{e}\right)-\theta_{e}\left(\mathrm{w}_{2}-\mathrm{c}_{2}\right)}{h}
$$

Proof. Since $\frac{\partial^{2} \Pi_{m}}{\partial e_{1}{ }^{2}}=-h<0$ then the manufacturer's profit function is concave in $e_{1}$ and therefore, $\frac{\partial \Pi_{m}}{\partial e_{1}}=0$ results in Equation (4).

The retailer's profit in general form can be expressed as:

$$
\begin{aligned}
& \Pi_{r}=\left(p_{1}-w_{1}\right)\left(\begin{array}{c}
a-b p_{1}+\tau e_{1}+\gamma s_{1}+\theta\left(p_{2}-p_{1}\right) \\
-\theta_{e}\left(e_{2}-e_{1}\right)+\theta_{s} s_{1}
\end{array}\right) \\
&+\left(p_{2}-w_{2}\right)\left(\begin{array}{c}
a-b p_{2}+\tau e_{2}+\theta\left(p_{1}-p_{2}\right) \\
-\theta_{e}\left(e_{1}-e_{2}\right)-\theta_{s} s_{1}
\end{array}\right)-\frac{k s_{1}^{2}}{2}
\end{aligned}
$$

Theorem 2. Under the decentralized scenario, the retailer's profit $\Pi_{r}$ is concave in both $p_{1}$ and $s_{1}$ if $\frac{2 k(b+\theta)}{\gamma^{2}(1+\theta)^{2}}>1$; hence by holding the condition, there is a unique optimal combination of decision variables $\left(p_{1}^{t *}, s_{1}^{t *}\right)$ that maximizes $\Pi_{r}$ :

$$
p_{1}^{t *}=\frac{\left(\begin{array}{c}
\left.k\left(c_{1}-w_{1}\right)\left(-\theta_{e}^{2}-\tau^{2}-2 \tau \theta_{e}\right)+k\left(c_{2}-w_{2}\right)\left(\theta_{e}^{2}+\tau \theta_{e}\right)\right) \\
+w_{1} h\left(b k+k \theta-2 \gamma \theta_{s}-\theta_{s}^{2}-\gamma^{2}\right)+w_{2} h\left(-k \theta+\gamma \theta_{s}+\theta_{s}^{2}\right)+ \\
p_{2} h\left(2 k \theta-\gamma \theta_{s}-\theta_{s}^{2}\right)-e_{2} h k \theta_{e}+a h k
\end{array}\right)}{h\left(2 b k+2 k \theta-2 \gamma \theta_{s}-\theta_{s}^{2}-\gamma^{2}\right)}
$$


Proof. To prove concavity, Hessian matrix of $\Pi_{r}$ is calculated as follows:

$H\left(\Pi_{r}\left(p_{1}, s_{1}\right)\right)=\left[\begin{array}{cc}-2(b+\theta) & \gamma+\theta_{s} \\ \gamma+\theta_{s} & -k\end{array}\right]$

Hessian matrix must be negative definite w.r.t $p_{1}$ and $s_{1}$. The first principal minor is negative and the second principal minor is positive if:

$\frac{2 k(b+\theta)}{\gamma^{2}(1+\theta)^{2}}>1$

By holding Condition (8) the Hessian matrix is negative definite and $\Pi_{r}$ is concave in both $p_{1}$ and $s_{1}$. The optimal values of the retailer's decision variables $p_{1}$ and $s_{1}$ can be obtained from the solution of $\frac{\partial \Pi_{\mathrm{r}}\left(\mathrm{p}_{1}, \mathrm{~s}_{1}\right)}{\partial \mathrm{p}_{1}}=0$ and $\frac{\partial \Pi_{\mathrm{r}}\left(\mathrm{p}_{1}, \mathrm{~s}_{1}\right)}{\partial \mathrm{s}_{1}}=0$ as:

$p_{1}^{t *}\left(s_{1}\right)=\frac{\left(a+\tau e_{1}+\gamma s_{1}-\theta_{e}\left(e_{2}-e_{1}\right)+\theta_{S} s_{1}+2 \theta\left(p_{2}\right)-\theta w_{2}+w_{1}(b+\theta)\right)}{2(b+\theta)}$

$s_{1}^{t *}\left(p_{1}\right)=\frac{\left(\mathrm{p}_{1}-\mathrm{w}_{1}\right)\left(\gamma+\theta_{s}\right)-\theta_{s}\left(\mathrm{p}_{2}-\mathrm{w}_{2}\right)}{k}$

Iterative solving the Equations (9)-(10) and replacing $e_{1}$ from Equation (4), we can simply derive Equations (6)-(7).

Theorem 3. Assuming larger net profit from selling each unit of the green product compared to non-green product (i.e. $p_{1}-w_{1}>p_{2}-w_{2}$ ), the retailer's profit function for a given $p_{1}$ is a strictly monotone increasing function in $s_{1}$ if $k \rightarrow 0$.

Proof. Calculating $\frac{\partial \Pi_{\mathrm{r}}\left(\mathrm{p}_{1}, \mathrm{~s}_{1}\right)}{\partial \mathrm{s}_{1}}=\left(\mathrm{p}_{1}-\mathrm{w}_{1}\right) \gamma+\gamma \theta\left[\left(\mathrm{p}_{1}-\mathrm{w}_{1}\right)-\left(\mathrm{p}_{2}-\mathrm{w}_{2}\right)\right]-\mathrm{ks}_{1}$ results in $\frac{\partial \Pi_{\mathrm{r}}\left(\mathrm{p}_{1}, \mathrm{~s}_{1}\right)}{\partial \mathrm{s}_{1}}>0$, when $k \rightarrow 0$, ceteris paribus.

The condition (8) is not satisfied under some circumstances, most likely when $k$ is relatively small or $\gamma$ is relatively large. Theorem 3 , shows that when $k \rightarrow 0$ optimization on $s_{1}$ results in $s_{1} \rightarrow+\infty$. From practical point of view, this means that when cost of green sales effort is negligible, then the retailer increases sales effort toward infinity to exploit from the demand increase. The same situation occurs if $\gamma$ takes large values. In reality, a large $\gamma$ means that any small effort results in a large boost in demand. Therefore, large values of $\gamma$ compared to $k$ motives the retailer to make more efforts. In such situations (i.e. negligible $k$ and/or large $\gamma$ ) the cost function is not concave since condition (8) does not satisfy; although these situations are interesting and profitable for the retailer and whole SC, they are not realistic in the real business environments.

\subsection{Integrated scenario}

In an integrated manner, it is assumed that there is a central decision maker who deciding on behalf of both channel members. The aim of the central decision maker is to maximize the whole channel profit. In this situation, Equation (11) represents the total profit of the supply chain. 


$$
\begin{aligned}
\Pi_{\mathrm{sc}}\left(\mathrm{p}_{1}, \mathrm{e}_{1}, \mathrm{~s}_{1}\right) & =\left(\mathrm{p}_{1}-\mathrm{c}_{1}\right)\left(\begin{array}{c}
a-b p_{1}+\tau e_{1}+\gamma s_{1} \\
+\theta\left(p_{2}-p_{1}\right)-\theta_{e}\left(e_{2}-e_{1}\right)+\theta_{s} s_{1}
\end{array}\right) \\
& +\left(\mathrm{p}_{2}-\mathrm{c}_{2}\right)\left(\begin{array}{c}
a-b p_{2}+\tau e_{2} \\
+\theta\left(p_{1}-p_{2}\right)-\theta_{e}\left(e_{1}-e_{2}\right)-\theta_{S} s_{1}
\end{array}\right)-\frac{h e_{1}^{2}}{2}-\frac{k s_{1}^{2}}{2}
\end{aligned}
$$

Theorem 4. Under the integrated scenario, the supply chain profit function $\Pi_{s c}$ is concave in $p_{1}, s_{1}$, and $e_{1}$ simultaneously if $\frac{2 k(b+\theta)}{(1+\theta)^{2}\left(\gamma^{2}+\frac{k}{h} \tau^{2}\right)}>1$; hence by holding the condition, there is a unique optimal combination of decision variables $\left(p_{1}^{i *}, s_{1}^{i *}, e_{1}^{i *}\right)$ that maximizes $\Pi_{s c}$ :

$p_{1}^{i *}=\frac{\left(\begin{array}{c}c_{1} k\left(b h-2 \tau \theta_{e}+h \theta-\theta_{e}^{2}-\tau^{2}\right)-c_{1} h\left(\theta_{s}^{2}+\gamma^{2}+2 \gamma \theta_{s}\right) \\ +c_{2} k\left(-h \theta+\tau \theta_{e}+\theta_{e}^{2}\right)+p_{2} k\left(2 h \theta-\tau \theta_{e}-\theta_{e}^{2}\right) \\ +h\left(c_{2}-p_{2}\right)\left(\gamma \theta_{s}+\theta_{s}^{2}\right)-e_{2} h k \theta_{e}+a h k\end{array}\right)}{2 h k(b+\theta)-h\left(\theta_{s}^{2}+\gamma^{2}\right)-k\left(\theta_{e}^{2}+\tau^{2}\right)-2 \gamma h \theta_{s}-2 k \tau \theta_{e}}$

$s_{1}^{i *}=\frac{\left(\begin{array}{c}c_{1} h\left(-b \theta_{s}-b \gamma-\gamma \theta-\theta \theta_{s}\right)+c_{2} h\left(2 b \theta_{s}-\gamma \theta+\theta \theta_{s}\right) \\ +p_{2} h\left(-2 b \theta_{s}+2 \gamma \theta\right)+\left(c_{2}-p_{2}\right)\left(-\tau^{2} \theta_{s}-\tau \theta_{e} \theta_{s}+\tau \gamma \theta_{e}+\gamma \theta_{e}^{2}\right)- \\ e_{2} h\left(\gamma \theta_{e}+\theta_{e} \theta_{s}\right)+a h\left(\theta_{s}+\gamma\right)\end{array}\right)}{2 h k(b+\theta)-h\left(\theta_{s}^{2}+\gamma^{2}\right)-k\left(\theta_{e}^{2}+\tau^{2}\right)-2 \gamma h \theta_{s}-2 k \tau \theta_{e}}$

$e_{1}^{i *}=-\frac{\left(\begin{array}{c}c_{1} k\left(b \theta_{e}+b \tau+\tau \theta+\theta \theta_{e}\right)+c_{2} k\left(-2 b \theta_{e}+\tau \theta-\theta \theta_{e}\right) \\ +p_{2} k\left(2 b \theta_{e}-2 \tau \theta\right)+\left(c_{2}-p_{2}\right)\left(\gamma^{2} \theta_{e}+\gamma \theta_{e} \theta_{s}-\tau \gamma \theta_{s}-\tau \theta_{s}^{2}\right)+ \\ e_{2} k\left(\tau \theta_{e}+\theta_{e}^{2}\right)-a k\left(\theta_{e}+\tau\right)\end{array}\right)}{2 h k(b+\theta)-h\left(\theta_{s}^{2}+\gamma^{2}\right)-k\left(\theta_{e}^{2}+\tau^{2}\right)-2 \gamma h \theta_{s}-2 k \tau \theta_{e}}$

Proof. To prove concavity, hessian matrix of $\Pi_{s c}$ is calculated as follows:

$H\left(\Pi_{s c}\left(p_{1}, s_{1}, e_{1}\right)\right)=\left[\begin{array}{ccc}-2(b+\theta) & \gamma+\theta_{s} & \tau+\theta_{e} \\ \gamma+\theta_{s} & -k & 0 \\ \tau+\theta_{e} & 0 & -h\end{array}\right]$

Hessian matrix must be negative definite w.r.t $p_{1}, s_{1}$ and $e_{1}$. The principal minors should have the following conditions:

$-2(b+\theta)<0$

$\frac{2 k(b+\theta)}{\gamma^{2}(1+\theta)^{2}}>1$

$\frac{2 k(b+\theta)}{(1+\theta)^{2}\left(\gamma^{2}+\frac{k}{h} \tau^{2}\right)}>1$

Since all parameters are positive thus the first principal minor given by Equation (15) is negative. The second and third principal minors are positive and negative respectively if Conditions (16)-(17) are satisfied. Since all parameters are positive, thus it is obvious that 
if Condition (17) is satisfied, then Condition (16) is guaranteed. By holding Condition (17) the Hessian matrix is negative definite and $\Pi_{s c}$ is concave in all decision variables. The optimal values of the supply chain decision variables $p_{1}, s_{1}$, and $e_{1}$ can be obtained from the solution of $\frac{\partial \Pi_{\mathrm{sc}}\left(\mathrm{p}_{1}, \mathrm{~s}_{1}, \mathrm{e}_{1}\right)}{\partial \mathrm{p}_{1}}=0, \frac{\partial \Pi_{\mathrm{sc}}\left(\mathrm{p}_{1}, \mathrm{~s}_{1}, \mathrm{e}_{1}\right)}{\partial \mathrm{s}_{1}}=0$, and $\frac{\partial \Pi_{\mathrm{sc}}\left(\mathrm{p}_{1}, \mathrm{~s}_{1}, \mathrm{e}_{1}\right)}{\partial \mathrm{e}_{1}}=0$ as:

$p_{1}^{i *}=\frac{\left(a+\tau e_{1}+\gamma s_{1}+2 \theta p_{2}-\theta_{e}\left(e_{2}-e_{1}\right)+\theta_{s} s_{1}-\theta c_{2}+c_{1}(b+\theta)\right)}{2(b+\theta)}$

$s_{1}^{i *}=\frac{\left(\mathrm{p}_{1}-\mathrm{c}_{1}\right)\left(\gamma+\theta_{s}\right)-\theta_{s}\left(\mathrm{p}_{2}-\mathrm{c}_{2}\right)}{k}$

$e_{1}^{i *}=\frac{\left(\mathrm{p}_{1}-\mathrm{c}_{1}\right)\left(\tau+\theta_{e}\right)-\theta_{e}\left(\mathrm{p}_{2}-\mathrm{c}_{2}\right)}{h}$

Iterative solving the Equations (18)- (20) we can simply derive Equations (12)- (14).

The condition (17) is not satisfied under some circumstances, most likely when $k$ and/or $h$ is relatively small or $\gamma$ is relatively large. From practical point of view, small values for $k$ and $h$ means low costs for green sales effort and green quality enhancements, respectively. In such situations, the retailer/manufacturer is expected to increase sales-effort/greenquality toward infinity to exploit from the demand increase without any significant increase in costs. Similarly, a large $\gamma$ means that any small effort makes a large boost in demand. Therefore, large values of $\gamma$ entices the retailer to make more efforts. Although these situations are interesting and profitable for the retailer and whole SC and at the same time cause that Condition (17) does not satisfy, they are not realistic in the real business environments.

Corollary 1. Whole system profit under integrated scenario is not less than the decentralized scenario.

Corollary 1 is intuitive. Under the integrated scenario, the whole SC is optimized while under the decentralized scenario, each member optimizes own profit independently. Thus the entire system profitability under the integrated scenario will not be less than the SC profit under the decentralized scenario. It is expected that the whole SC profit under the integrated scenario will be greater than the decentralized scenario if each member's profit depends on the other member's decisions, which is the case in this study.

Corollary 2. There is no guarantee for more profitability of all SC members under the integrated scenario.

As it is obvious, more profit for the whole channel does not mean more profit for all channel members necessarily. Although by changing decisions from decentralized to the integrated scenario the whole SC profit increases, this situation may make one member worse off. It means that all advantage of integrated decision making may be acquired only by one member and make the other one worsened.

To overcome this issue in the next section a collaboration model is proposed. 


\subsection{Collaboration scenario}

Integrated decision making needs a central decision maker that has the authority of making decisions on behalf of channel members. However, establishing such a central decision maker is impossible when channel members are independent economic entities. In other words, it is possible that the obtained solution makes one member better-off while the other member is worse-off. In such situation, from practical point of view, the affected member does not accept to participate in the integrated decision-making. In such situations, collaboration model should be established between channel members. Under the collaboration scenario, channel members cooperate to maximize the profit of the whole channel while the profits of the retailer and manufacturer remain in a higher level than the decentralized model. Under such circumstances, channel members have enough incentive to participate in the collaborative decision making. The collaboration scenario should create a win-win solution for both members. Under the collaboration scenario each channel member can negotiate on its share of the surplus profit based on his bargaining power or market domination. Level of members' market domination in the proposed model is shown by parameters ' $\alpha$ ' and ' $\beta$ ' where $0<\alpha+\beta \leq 1$. ' $\alpha$ ' is defined as the factor of retailer's dominancy and ' $\beta$ ' represents dominancy of the manufacturer. Previous studies in the literature of supply chain coordination also proposed somehow similar procedures for dividing the surplus (e.g. Li and Liu, 2006; Wang et al., 2015; Heydari and Norouzinasab, 2015; Saha and Goyal, 2015). When the retailer is known as a dominant member in the channel, $\alpha$ takes a larger value close to 1 and most of the surplus profit is acquired by the retailer. On the contrary, if the manufacturer is a dominant channel member, then $\beta$ takes a larger value and most of the surplus is gained by the manufacturer. In practice, marketdominancy/bargaining-power can be measured based on indicators such as market share, brand popularity, level of monopoly/monopsony/oligopoly, etc., which is beyond the scope of this study. Both ' $\alpha$ ' and ' $\beta$ ' are considered as an input parameter for the model. The collaboration scenario can be formulated as a mathematical programming problem. Similar to the integrated scenario, the objective of the proposed mathematical programming model is to maximize the total channel profit. However, to create enough motivations for members to accept the collaborative solution, the profit maximization problem is subjected to certain constraints to ensure more profit for both members compared to the decentralized scenario. 


$$
\operatorname{Max} \Pi_{\mathrm{sc}}\left(\mathrm{p}_{1}, \mathrm{e}_{1}, \mathrm{~s}_{1}\right)=\left(\begin{array}{c}
\left(\mathrm{p}_{1}-\mathrm{c}_{1}\right)\left(\begin{array}{c}
a-b p_{1}+\tau e_{1}+\gamma s_{1}+\theta\left(p_{2}-p_{1}\right) \\
-\theta_{e}\left(e_{2}-e_{1}\right)+\theta_{s} s_{1}
\end{array}\right) \\
+\left(\mathrm{p}_{2}-\mathrm{c}_{2}\right)\left(\begin{array}{c}
a-b p_{2}+\tau e_{2}+\theta\left(p_{1}-p_{2}\right) \\
-\theta_{e}\left(e_{1}-e_{2}\right)-\theta_{s} s_{1}
\end{array}\right)-\frac{h e_{1}^{2}}{2}-\frac{k s_{1}^{2}}{2}
\end{array}\right)
$$

s.t.

$$
\begin{aligned}
& \Pi_{r}^{c o}=\left(p_{1}-w_{1}\right)\left(\begin{array}{c}
a-b p_{1}+\tau e_{1}+\gamma s_{1}+\theta\left(p_{2}-p_{1}\right) \\
-\theta_{e}\left(e_{2}-e_{1}\right)+\theta_{s} s_{1}
\end{array}\right) \\
& +\left(p_{2}-w_{2}\right)\left(\begin{array}{c}
a-b p_{2}+\tau e_{2}+\theta\left(p_{1}-p_{2}\right) \\
-\theta_{e}\left(e_{1}-e_{2}\right)-\theta_{s} s_{1}
\end{array}\right)-\frac{k s_{1}^{2}}{2} \\
& \geq \Pi_{r}^{t *}+\alpha\left(\Pi_{s c}^{i *}-\Pi_{s c}^{t *}\right) \\
& \Pi_{m}^{c o}=\left(w_{1}-c_{1}\right)\left(\begin{array}{c}
a-b p_{1}+\tau e_{1}+\gamma s_{1}+\theta\left(p_{2}-p_{1}\right) \\
-\theta_{e}\left(e_{2}-e_{1}\right)+\theta_{s} s_{1}
\end{array}\right) \\
& +\left(w_{2}-c_{2}\right)\left(\begin{array}{c}
a-b p_{2}+\tau e_{2}+\theta\left(p_{1}-p_{2}\right) \\
-\theta_{e}\left(e_{1}-e_{2}\right)-\theta_{s} s_{1}
\end{array}\right)-\frac{h e_{1}^{2}}{2} \\
& \geq \Pi_{m}^{t *}+\beta\left(\Pi_{s c}^{i *}-\Pi_{s c}^{t *}\right) \\
& 0<\alpha+\beta \leq 1 \\
& p_{1}, s_{1}, e_{1} \in \mathrm{R}^{+}
\end{aligned}
$$

The objective function (21) aims to maximize the total channel profit. Constraint (22) ensures that the retailer's profit after the establishment of the collaboration strategy is more than the profit in the decentralized decision making scenario. In other words, term ' $\alpha\left(\Pi_{s c}^{i *}-\Pi_{s c}^{t *}\right)$ ' in the right-hand side of the inequality (22) guarantees enough incentives for the retailer to participate in the collaboration scenario. Similarly, Constraint (23) ensures more profit for the manufacturer after applying the collaboration scenario than the decentralized scenario. Term ' $\beta\left(\Pi_{s c}^{i *}-\Pi_{s c}^{t *}\right)$ ' in the right-hand side of the inequality (23) creates enough incentives for the manufacturer to participate in the collaboration scenario.

\section{Numerical analyses}

To numerically evaluate the models, three examples have been examined. Datasets for the investigated examples are shown in Table 2. All datasets satisfy assumptions and requirements of the proposed models. We employ rather general data to illustrate the analytical findings as well as show the applicability of the proposed model. Due to difficulties of accessing the real industry data, we select datasets largely consistent with the used data by previous works in the related literature (e.g. Zhao \& Wei, 2014; Gao et al., 2016; Ma et al., 2013b). In addition, employed datasets do not violate the common and rational relationship between parameters (e.g. $c_{2} \leq w_{2} \leq$ $\left.p_{2}\right)$. 
Table 2. Three numerical examples datasets.

\begin{tabular}{cccccccccccccc}
\hline & $\boldsymbol{a}$ & $\boldsymbol{b}$ & $\boldsymbol{\tau}$ & $\boldsymbol{\gamma}$ & $\boldsymbol{w}_{\mathbf{1}}$ & $\boldsymbol{w}_{2}$ & $\boldsymbol{c}_{1}$ & $\boldsymbol{c}_{2}$ & $\boldsymbol{h}$ & $\boldsymbol{k}$ & $\boldsymbol{\theta}$ & $\boldsymbol{p}_{2}$ & $\boldsymbol{e}_{2}$ \\
\cline { 2 - 11 } Ex. 1 & 60 & 1 & 1.5 & 0.75 & 31.5 & 20 & 4 & 2 & 3.5 & 4 & 0.5 & 25 & 0 \\
Ex. 2 & 100 & 0.3 & 0.2 & 0.1 & 17 & 14 & 9 & 7.5 & 0.35 & 0.3 & 0.4 & 20 & 1 \\
Ex. 3 & 150 & 0.5 & 0.3 & 0.3 & 19 & 15 & 14 & 11 & 1 & 1 & 1 & 20 & 1.1 \\
\hline
\end{tabular}

\subsection{Decentralized vs. Integrated scenario}

For the given datasets in Table 2, the amount of all decision variables, both members' profits, and total channel profit in both integrated and decentralized models are reported in Table 3. According to Table 3, as expected, the total channel profit in the integrated scenario is higher than the decentralized scenario. In all examples, the equilibrium amounts of green product retail price, green product quality, and sales efforts of the green product increase by shifting the decision structure from the decentralized to the integrated scenario. In addition, under the integrated scenario the green product demand increases while the non-green product demand decreases. It is worth mentioning that in all examples, the total demand for both products is higher under the integrated scenario which in turn means more sales volume for the SC. Although the integrated scenario creates higher profit for the total channel, this scenario does not necessarily create higher profit for both members. Comparing the manufacturer's profit under the decentralized scenario with the integrated scenario reveals that the manufacturer does not benefit from shifting to the integrated scenario. In other words, although the manufacturer, in looking for better position for the total channel, sets higher values for the environmental quality of green quality, all the benefits of integrated scenario are acquired by the retailer. As a result, the integrated scenario is not an acceptable decision scenario for the manufacturer. To convince the manufacturer, the retailer needs an alternative decision scenario that maximizes total channel profit subject to a guaranteed gain for the manufacturer as well as the retailer.

Table 3. Decision variables and profit functions in decentralized vs. integrated scenario

\begin{tabular}{|c|c|c|c|c|c|c|c|c|}
\hline \multicolumn{9}{|c|}{ Decentralized Scenario } \\
\hline & $p_{1 r}^{t *}$ & $s_{1 r}^{t *}$ & $e_{1 m}^{t *}$ & $D_{1}{ }^{t *}$ & $D_{2}{ }^{t *}$ & $\Pi_{m}^{t *}$ & $\Pi_{r}^{t *}$ & $\Pi_{s c}^{t *}$ \\
\hline Ex. 1 & 53.23 & 5.64 & 13.82 & 30.10 & 36.63 & 1152.8 & 773.6 & 1926.4 \\
\hline Ex. 2 & 91.69 & 34.06 & 4.91 & 49.88 & 121.20 & 1182.6 & 4278.8 & 5461.4 \\
\hline Ex. 3 & 74.44 & 31.76 & 1.80 & 78.15 & 185.03 & 1129.3 & 4753.2 & 5882.5 \\
\hline \multicolumn{9}{|c|}{ Integrated Scenario } \\
\hline & $p_{1 r}^{i *}$ & $s_{1 r}^{i *}$ & $e_{1 m}^{i *}$ & $D_{1}{ }^{i *}$ & $D_{2}{ }^{i *}$ & $\Pi_{\mathrm{m}}^{i *}$ & $\Pi_{\mathrm{r}}^{i *}$ & $\Pi_{\mathrm{sc}}^{i *}$ \\
\hline Ex. 1 & 56.12 & 12.50 & 28.58 & 66.68 & 24.44 & 844.4 & 1451.5 & 2295.9 \\
\hline Ex. 2 & 104.07 & 42.70 & 73.20 & 61.55 & 120.34 & 337.0 & 5807.2 & 6144.2 \\
\hline Ex. 3 & 81.73 & 37.94 & 37.94 & 92.60 & 179.63 & 461.8 & 5987.4 & 6449.2 \\
\hline
\end{tabular}




\subsection{Collaboration scenario}

Table 4 represents the results of applying dataset from example 1 on the collaboration model for various combinations of $\alpha$ and $\beta$. From Table 4 it can be inferred that by reduction of $\alpha$ (the retailer's share) and increase of $\beta$ (the manufacturer's share) both the retail price and environmental quality of green product decrease in all test problems. From practical point of view, it means that considering more share for the retailer causes producing expensive but with higher environmental quality of products. Instead, considering more share for the manufacturer leads in producing cheaper in lower green quality products. Positive values for $\Delta \Pi_{s c}^{*}$ shows that the proposed collaboration model creates more profit for the channel than the decentralized scenario, and at the same time, both the retailer and the manufacturer make better-off $\left(\Delta \Pi_{m}^{*}>0\right.$ and $\left.\Delta \Pi_{r}^{*}>0\right)$.

Table 4. Collaboration model results under various combinations of $\alpha$ and $\beta$ (Ex. 1)

\begin{tabular}{|c|c|c|c|c|c|c|c|c|c|}
\hline & $p_{1}^{c o *}$ & $s_{1}^{c o *}$ & $e_{1}^{c o *}$ & $\Pi_{m}^{c o *}$ & $\Pi_{r}^{c o *}$ & $\Pi_{s c}^{c o *}$ & $\Delta \Pi_{m}^{*}$ & $\Delta \Pi_{r}^{*}$ & $\Delta \Pi_{s c}^{*}$ \\
\hline $\begin{array}{l}\alpha=0.9 \\
\beta=0.05\end{array}$ & 51.40 & 11.90 & 24.29 & 1171.29 & 1107.02 & 2279.31 & 18.49 & 333.42 & 351.91 \\
\hline $\begin{array}{l}\alpha=0.45 \\
\beta=0.4\end{array}$ & 49.16 & 11.71 & 22.45 & 1300.61 & 957.79 & 2258.40 & 147.81 & 184.19 & 332.00 \\
\hline $\begin{array}{l}\alpha=0.3 \\
\beta=0.5\end{array}$ & 48.47 & 11.66 & 21.91 & 1337.56 & 913.29 & 2250.85 & 184.76 & 139.69 & 324.45 \\
\hline $\begin{array}{l}\alpha=0.2 \\
\beta=0.6\end{array}$ & 47.76 & 11.63 & 21.36 & 1374.51 & 867.83 & 2242.34 & 221.71 & 94.23 & 315.94 \\
\hline $\begin{array}{l}\alpha=0.05 \\
\beta=0.75\end{array}$ & 46.64 & 11.92 & 20.50 & 1429.93 & 797.67 & 2227.60 & 277.13 & 24.07 & 301.20 \\
\hline
\end{tabular}

\subsection{Sensitivity analyses}

To investigate the behavior of the proposed models, a set of sensitivity analyses on cost parameters $h$ and $k$ and also coefficients $\tau$ and $\gamma$ are conducted. Dataset for sensitivity analyses are given from example 1 , and it is assumed that $\alpha=\beta=0.35$.

\subsubsection{Impact of greening cost}

One of the most important factors in the proposed model is the greening cost $h$ which can affect the solution's quality. It is expected that increasing $h$ more than a threshold cause some troubles in the model. Increasing $h$ means that more investment is required for producing a green product which in turn causes an unaffordable price of green products for the customers.

Figure 1 illustrates the manufacturer's profit against $h$. According to Figure 1, for all values of $h$, the manufacturer's profit under collaboration is more than the decentralized scenario which implies that the collaboration scenario is acceptable to the manufacturer's 
viewpoint. Although the manufacturer's profit in the integrated scenario is sensitive to $h$, under the collaboration scenario, it is not sensitive to $h$. Indeed, by increasing $h$, the manufacturer sets the decision variable $e_{1}$ in lower values to prevent additional costs (see Figure 2). This action repels the impact of increasing $h$. According to Figure 2, the equilibrium amount of environmental quality in the collaboration scenario is more than the decentralized scenario. From the practical viewpoint, this behaviour implies that the proposed collaboration model is capable of enhancing channel greenness with respect to decentralized decision making. In addition, the collaboration model creates a greener channel than the integrated scenario when the greening cost coefficient $h$ is high enough. Moreover, as expected, by increasing $h$, the channel will be less green in all three decision making scenarios which is a direct result of high greening costs. Under the integrated decision making, increase of the manufacturer's profit by the increase of $h$ is not, in fact, due to increase in $h$, but it is a direct result of the retailer's decision on $p_{1}$ (see Figure 4) which stimulates demand and causes an increase on the supply chain sales volume.

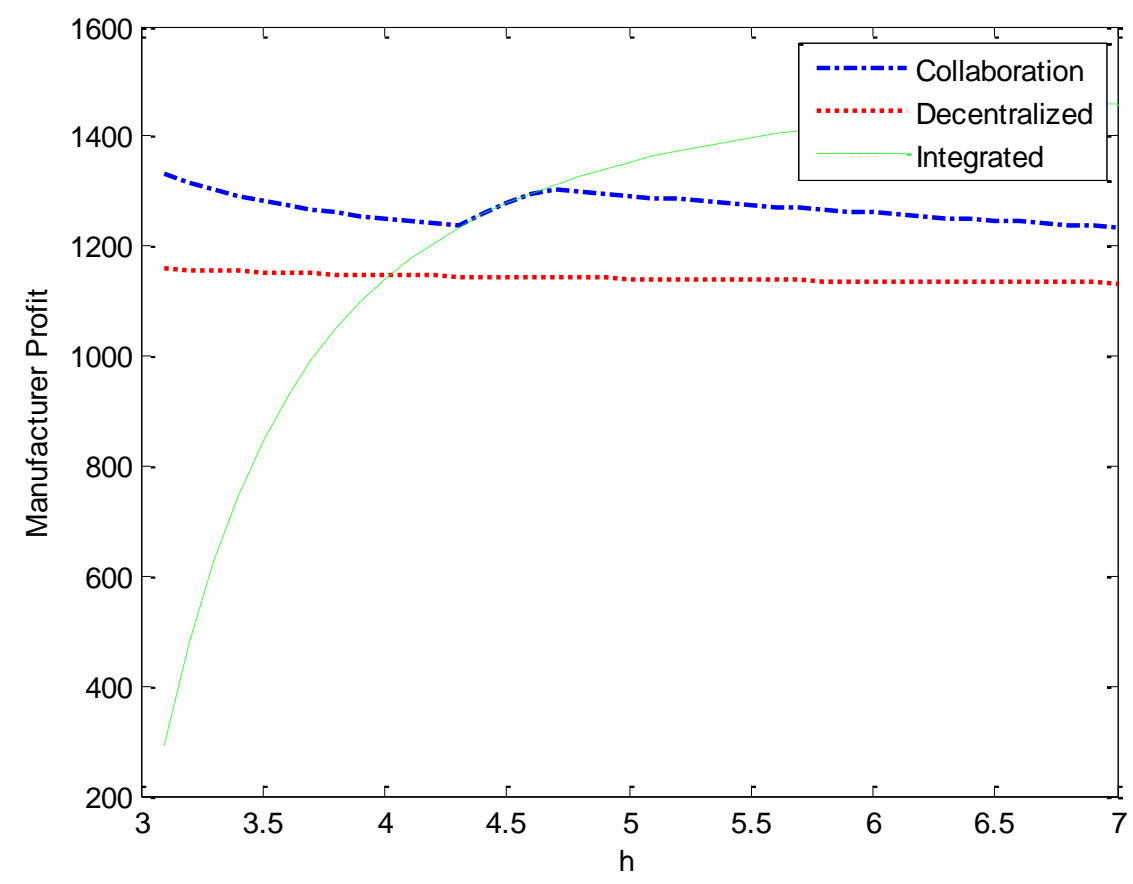

Figure 1. The effect of greening cost $h$ on the manufacturer's profit. 


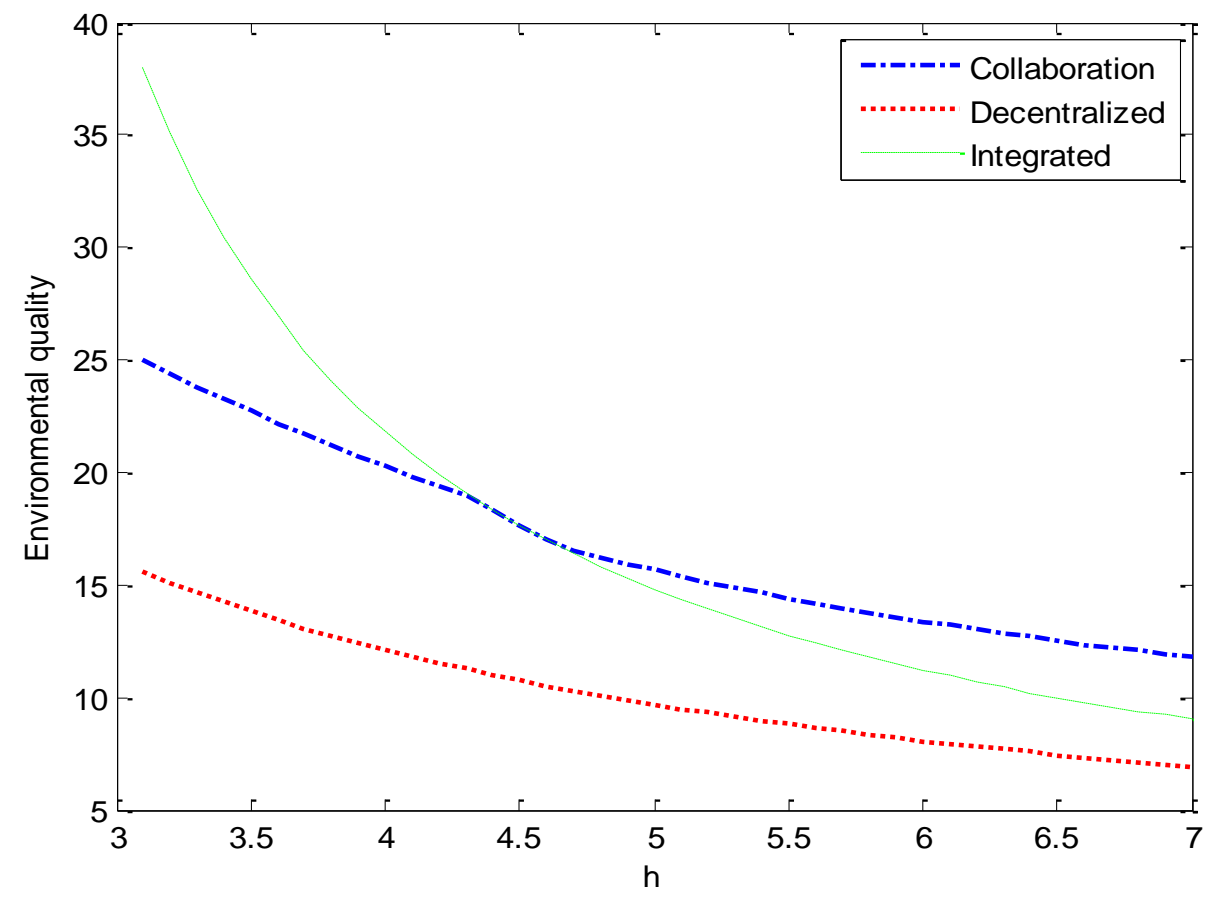

Figure 2. The effect of greening cost $h$ on the manufacturer's decision variable $e_{1}$.

As it can be seen in Figure 3, the collaboration scenario results in more profit for the retailer than the decentralized scenario, and therefore, the model is acceptable to the retailer's viewpoint for various values of $h$. According to Figures 4 and 5, by increasing $h$, the retailer sets both of its decision variables in lower values in all the three scenarios. This behavior can be considered as the retailer's reaction to the manufacturer's decision in reducing environmental quality of the green product (see Figure 2). As a result, to prevent the additional costs, the retailer reduces the equilibrium price of the green product as well as its green sales efforts based on the new equilibrium condition. However, for all values of $h$ the collaboration model results in lower retail price and higher sales efforts (see Figures 4 and 5) and at the same time higher environmental quality (see Figure 2) than the decentralized scenario which implies that the channel offers less expensive with higher environmental quality products to the customers. This behavior is an interesting feature of the proposed collaboration model, which results in more satisfied customers as well as more sustainable operations at the same time. 


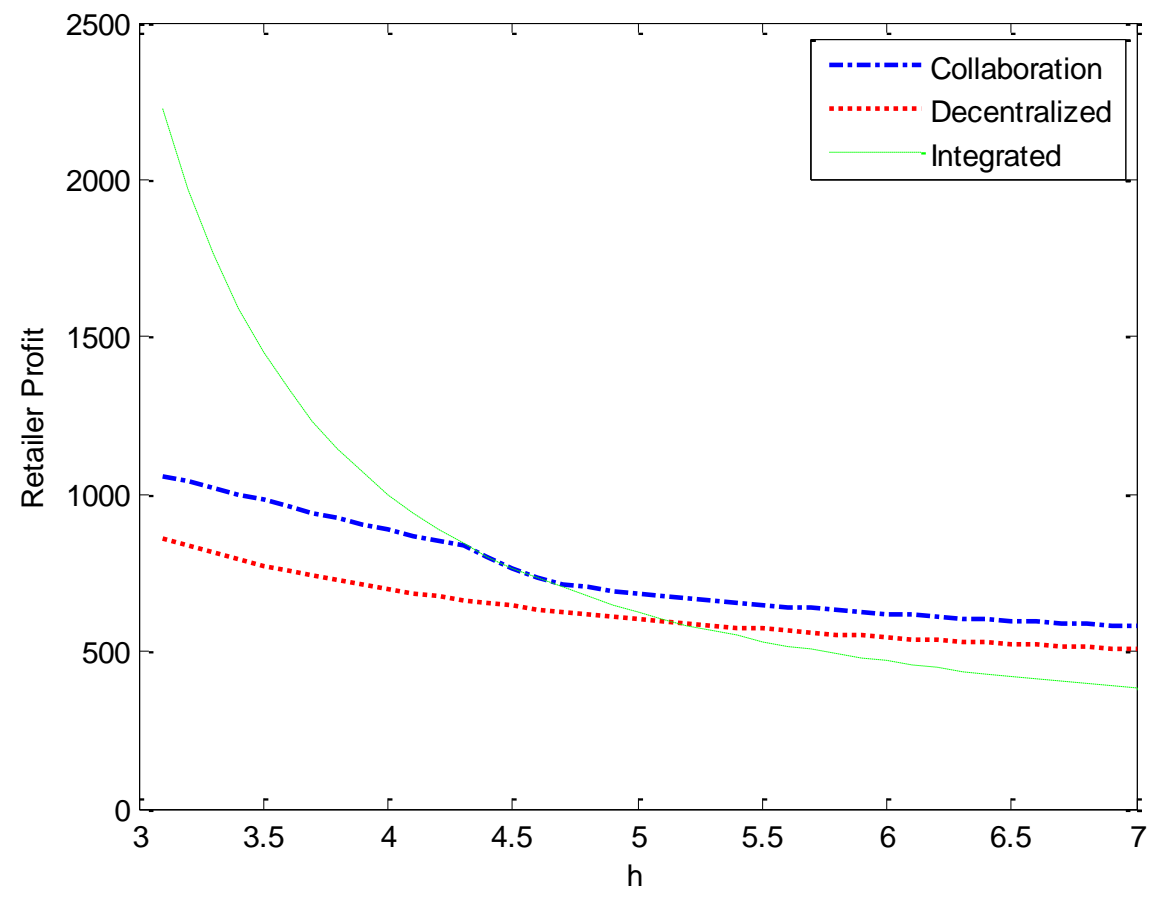

Figure 3. The effect of greening cost $h$ on the retailer's profit.

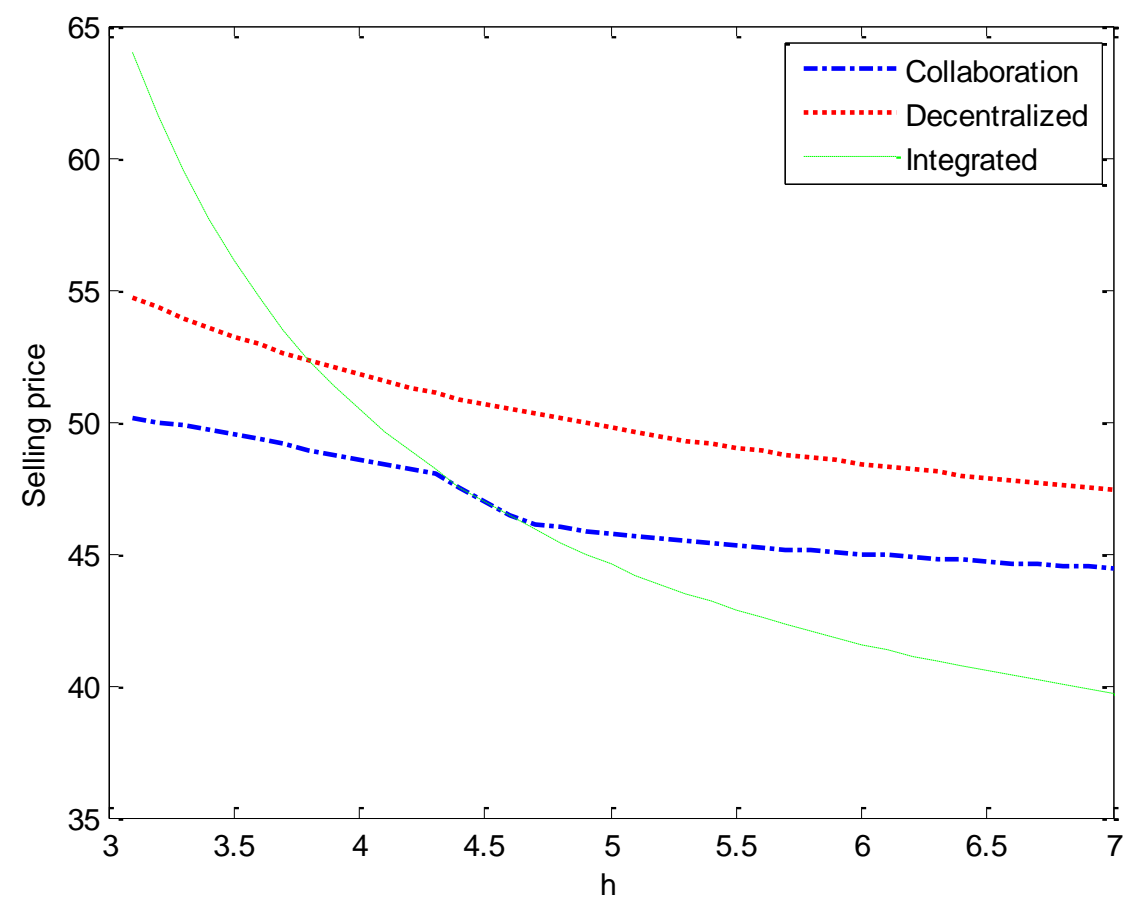

Figure 4. The effect of greening cost $h$ on the retailer's decision variable $p_{1}$. 


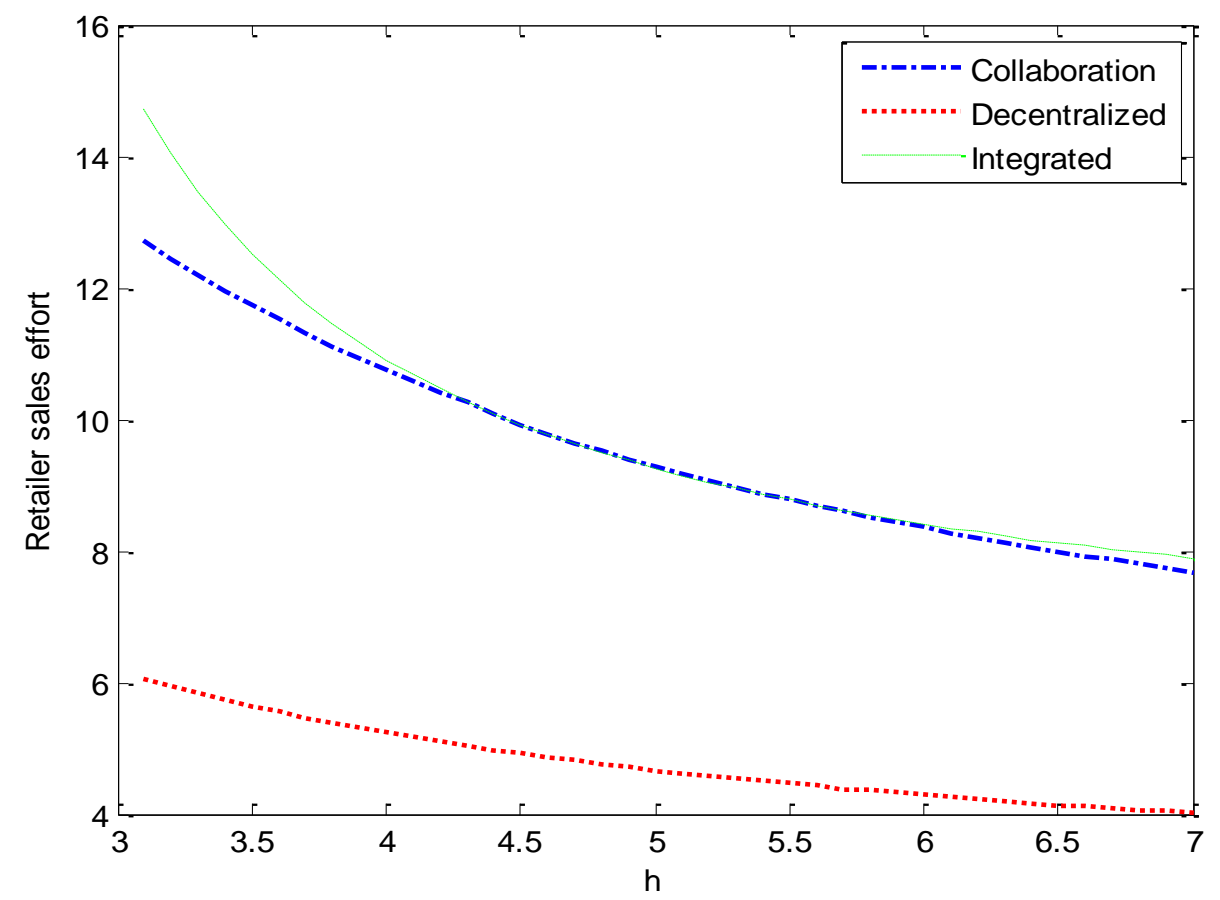

Figure 5. The effect of greening cost $h$ on the retailer's decision variable $s_{1}$.

As shown in Figure 6, the total channel profit decreases by increasing $h$ which is a rational behaviour. At the same time, according to Figure 6, the proposed collaboration model results in more profit for the whole channel than the decentralized model. Figure 6 implies that the performance of the proposed collaboration model for all values of $h$ is fairly close to the integrated model. 


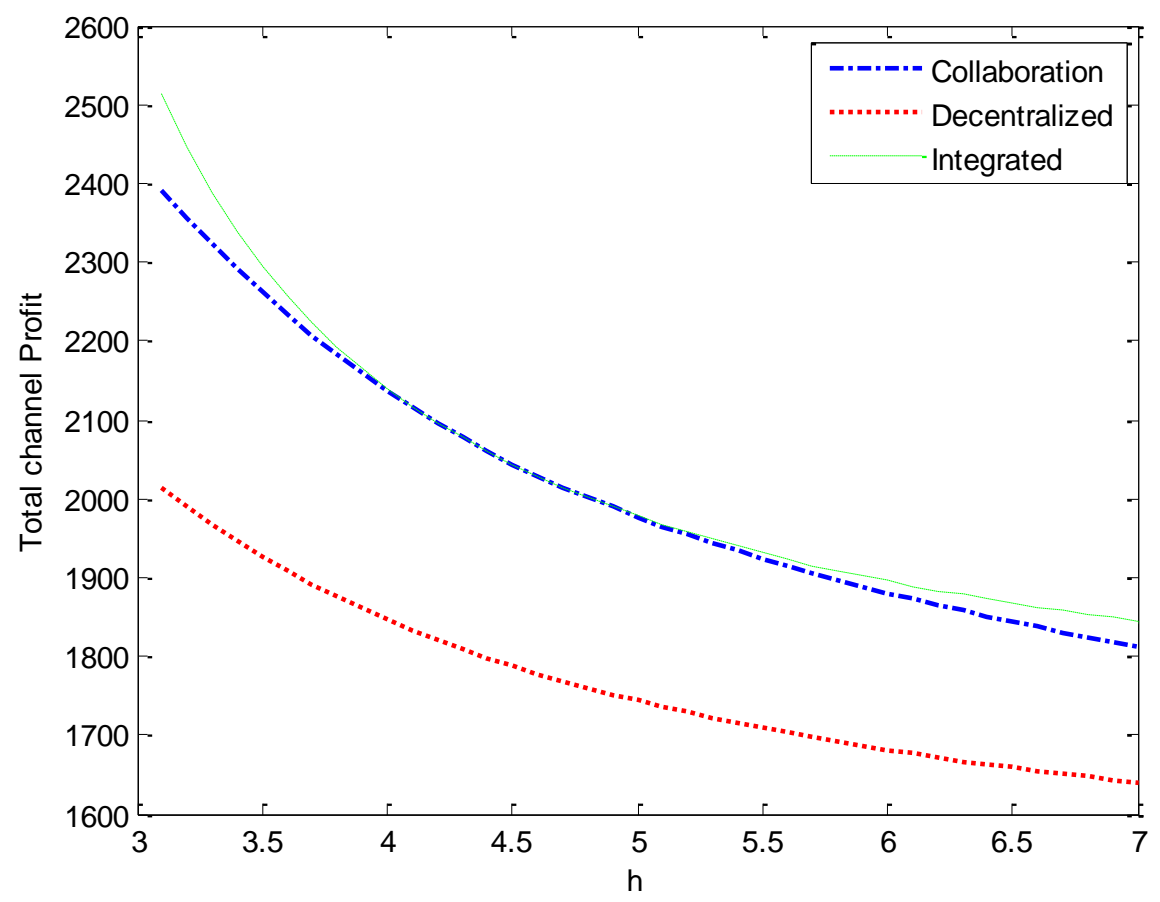

Figure 6. The effect of greening cost $h$ on the total channel profit.

\subsubsection{Impact of sales effort cost}

Sales effort cost $k$ is a critical cost factor that can affect the sales effort amount and consequently, influences demand and sales volume of green product in the proposed models. Figure 7 illustrates the retailer's profit against $k$; as it can be seen in Figure 7, the retailer's profit under the collaboration scenario is more than the decentralized model that implies on applicability of the proposed model from the retailer's viewpoint for various values of $k$. On the other hand, according to Figure 7, in all three scenarios, the retailer's profit decreases by increasing $k$, which is rational due to expensive sales effort costs. To prevent additional costs by increasing $k$, the retailer reduces $s_{1}$ (see Figures 9). This action repels the impact of increasing $k$ and prevents the retailer's profit reduction under the decentralized model. At the same time, to neutralize the impact of reduced $s_{1}$ on demand and maintaining demand volume, the retailer reduces $p_{1}$. On the other hand, our experiments reveal that under the collaboration scenario, the retailer sets the retailprice/sales-effort amount in lower/higher levels than the decentralized scenario. Such tuning of decision variables in the collaboration scenario causes an increased demand for the green product and increases the channel sales volume. 


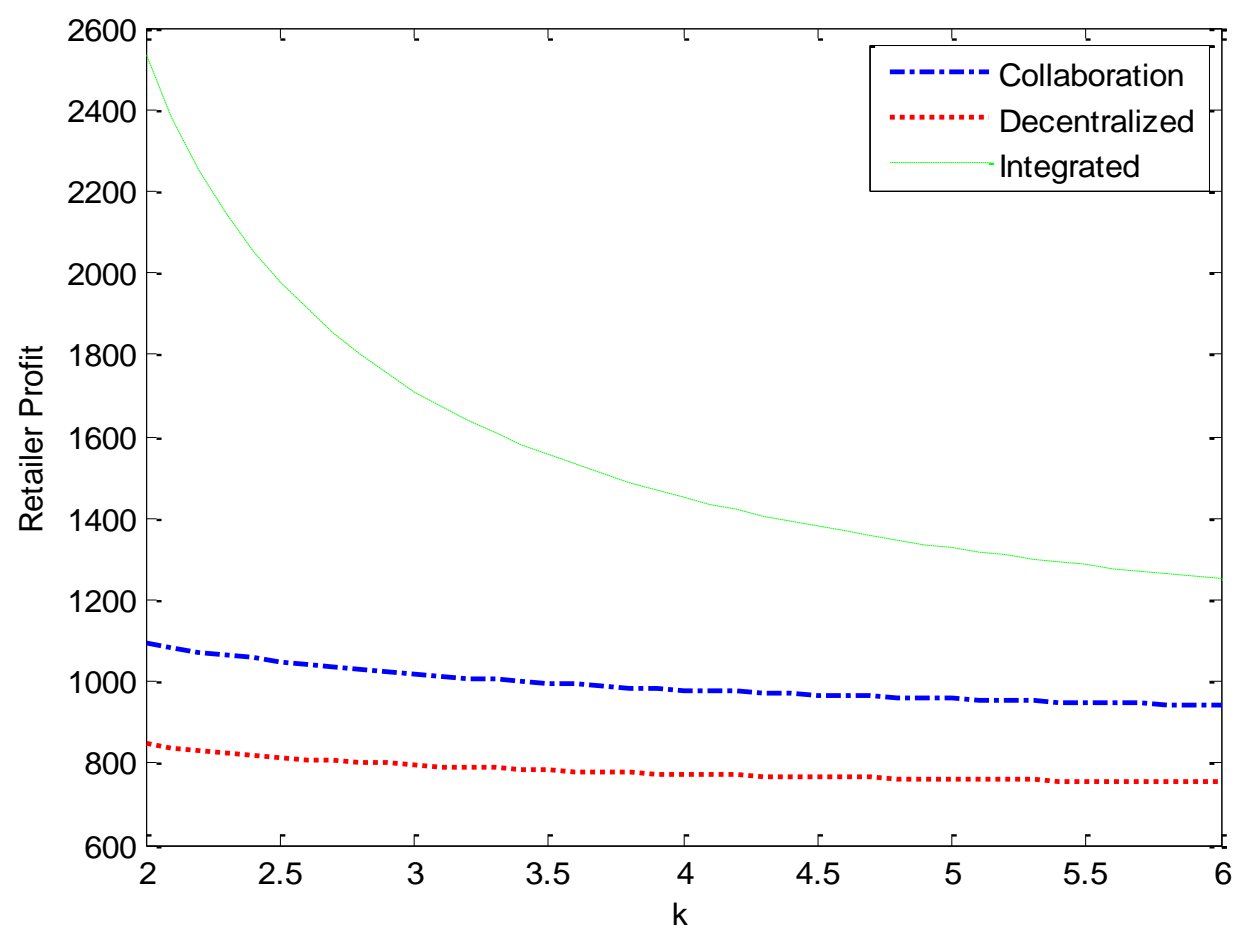

Figure 7. The effect of sales effort cost $k$ on the retailer's profit.

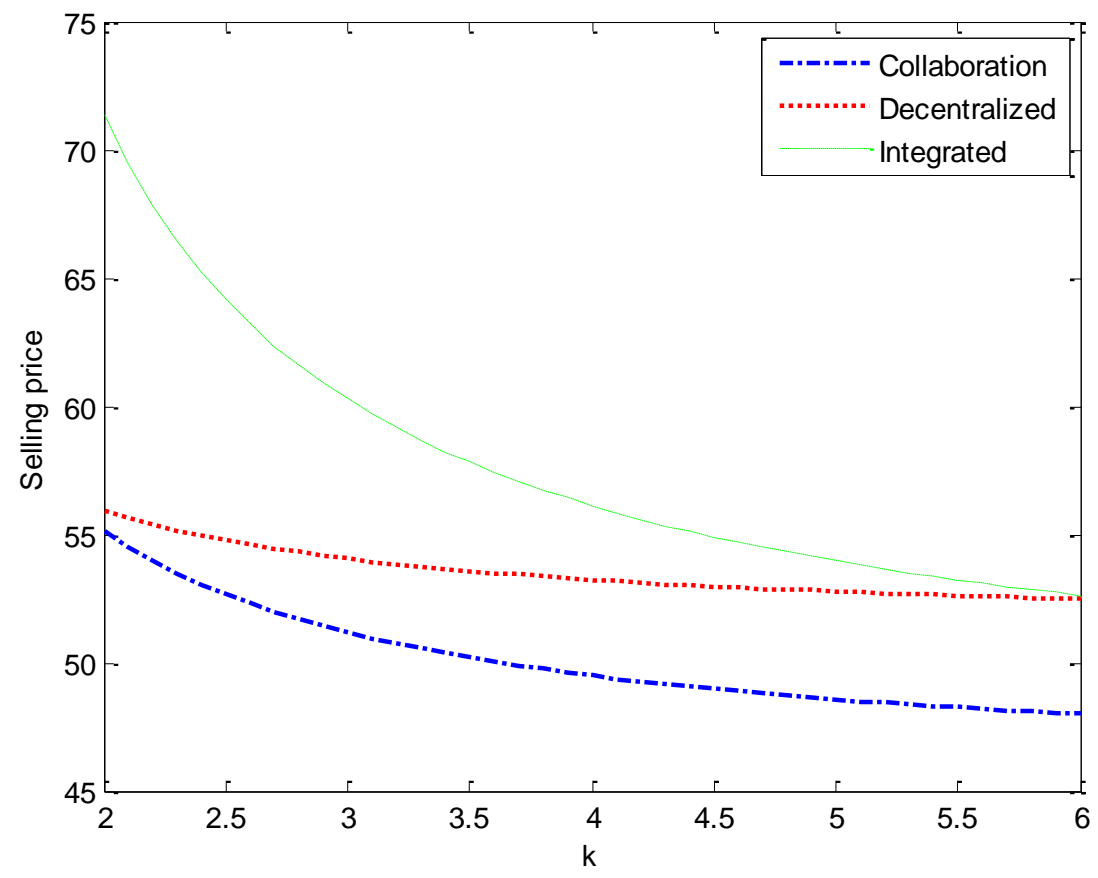

Figure 8 . The effect of sales effort cost $k$ on the retailer's decision variable $p_{1}$. 


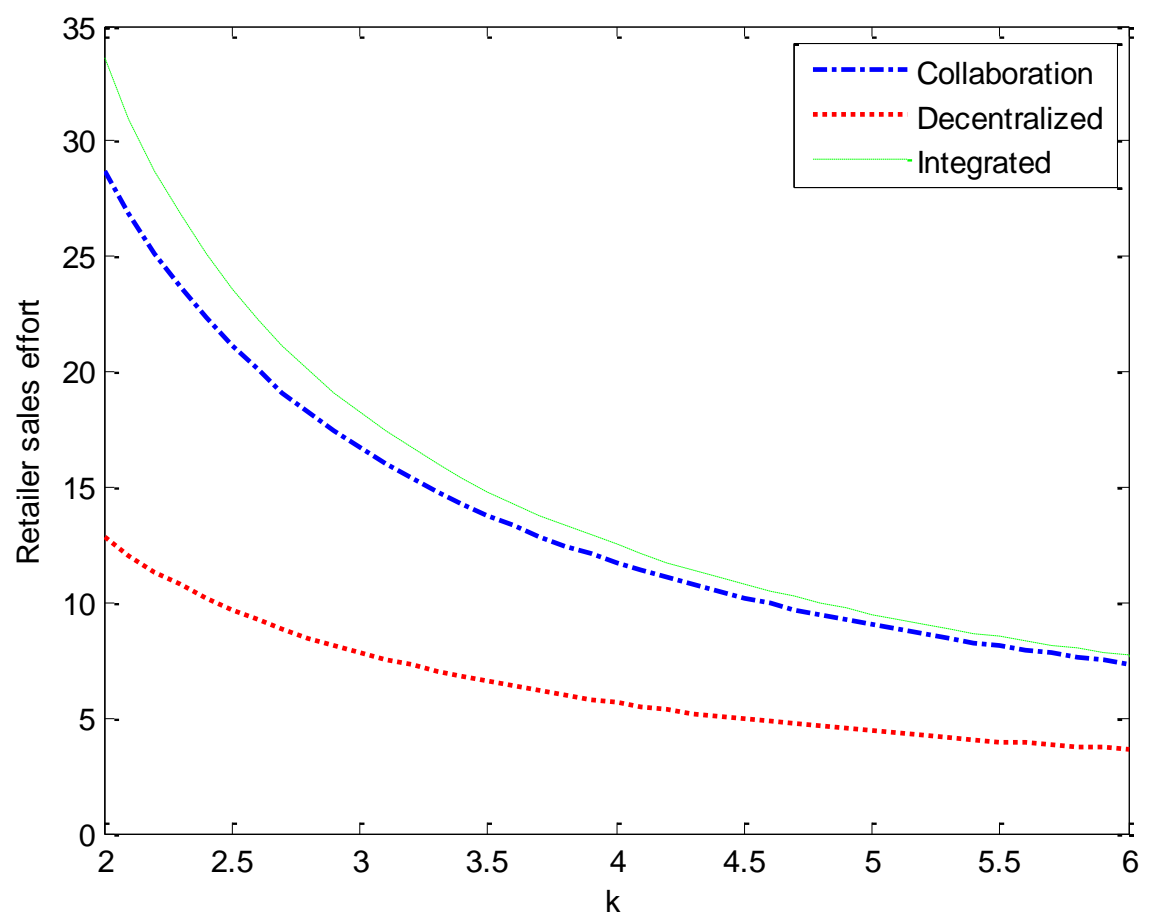

Figure 9. The effect of sales effort cost $k$ on the retailer's decision variable $s_{1}$.

As it can be seen in Figure 10, for all values of $k$, the collaboration model results in more profit for the manufacturer than the decentralized decision making, and therefore, the model is acceptable to the manufacturer's viewpoint. According to Figure 11, parameter $k$ does not have any significant impact on the manufacturer's decision $e_{1}$ under decentralized and collaboration scenarios, which implies that the manufacturer's decision does not change when sales effort cost is increased or decreased. The reason for this behaviour can be found in Figures 8 and 9 where the retailer sets lower price and higher sales efforts by increasing $k$. Indeed, the two decisions of retailer on $p_{1}$ and $s_{1}$ neutralize each other and repel the impact of increasing $k$. As a result, the condition remains somewhat stable for the manufacturer and therefore, the manufacturer's decision $e_{1}$ under the proposed collaboration scenario remains unchanged by changing $k$. On the other hand, according to Figure 11, the equilibrium amount of environmental quality in the collaboration scenario is more than the traditional one that means creating a greener channel under the collaboration scenario than the decentralized scenario.

Comparing total channel profits in all three scenarios for various values of $k$ reveals that the proposed collaboration model creates more profit for the whole channel than the decentralized model. In addition, the collaboration model results in an outcome for the total channel fairly close to the integrated model (see Figure 12) without making any of the channel members worse-off (see Figures 7 and 10). 


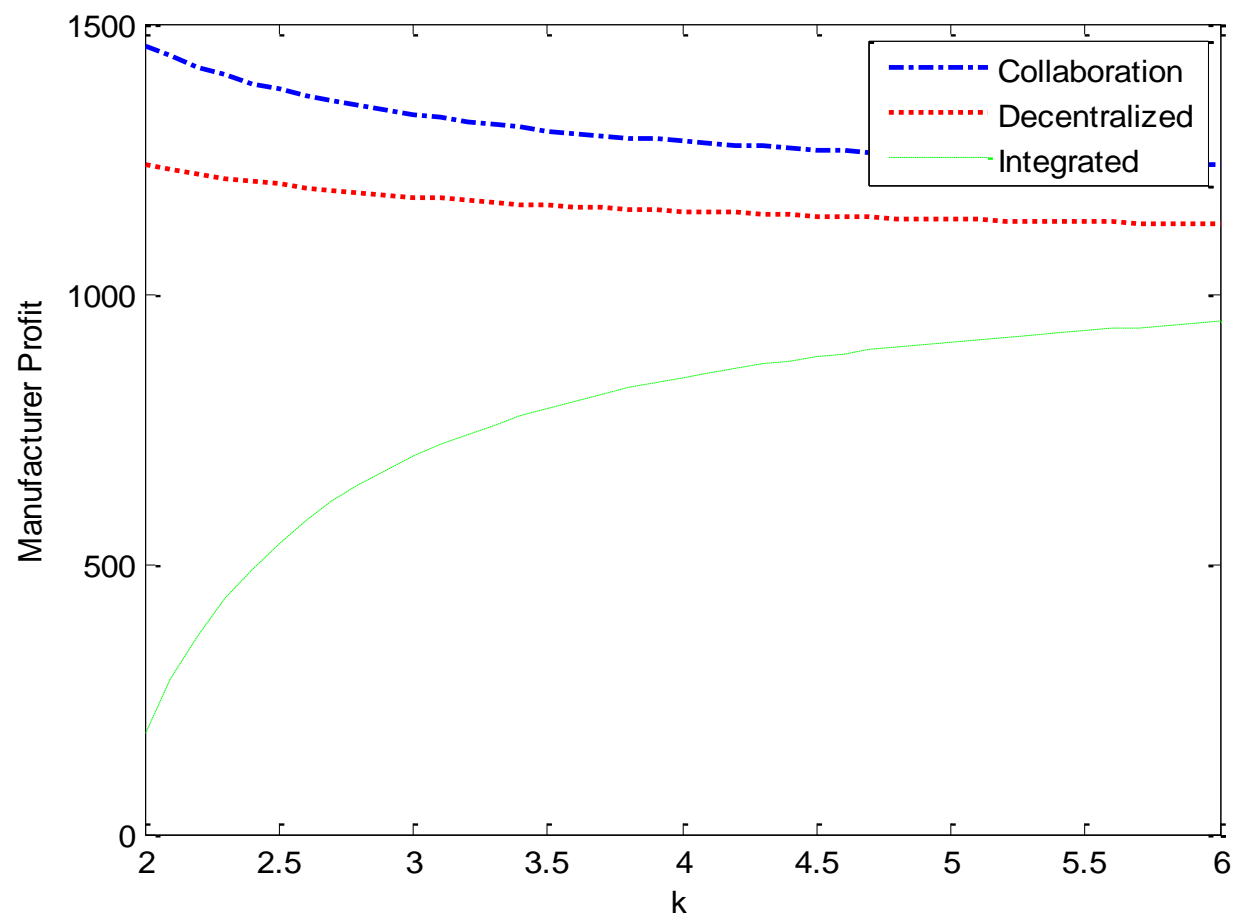

Figure 10. The effect of sales effort cost $k$ on the manufacturer's profit.

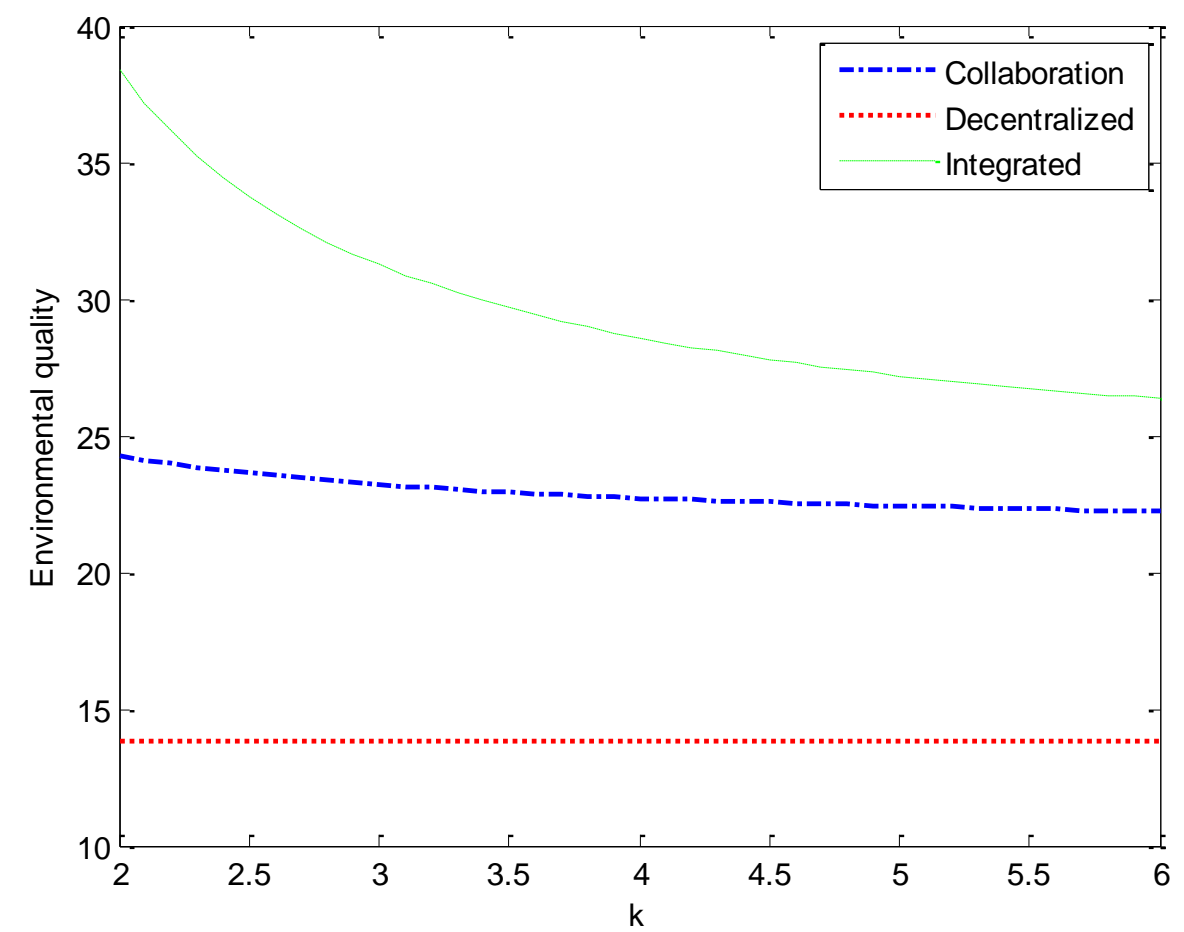

Figure 11. The effect of sales effort cost $k$ on the manufacturer's decision variable $e_{1}$. 


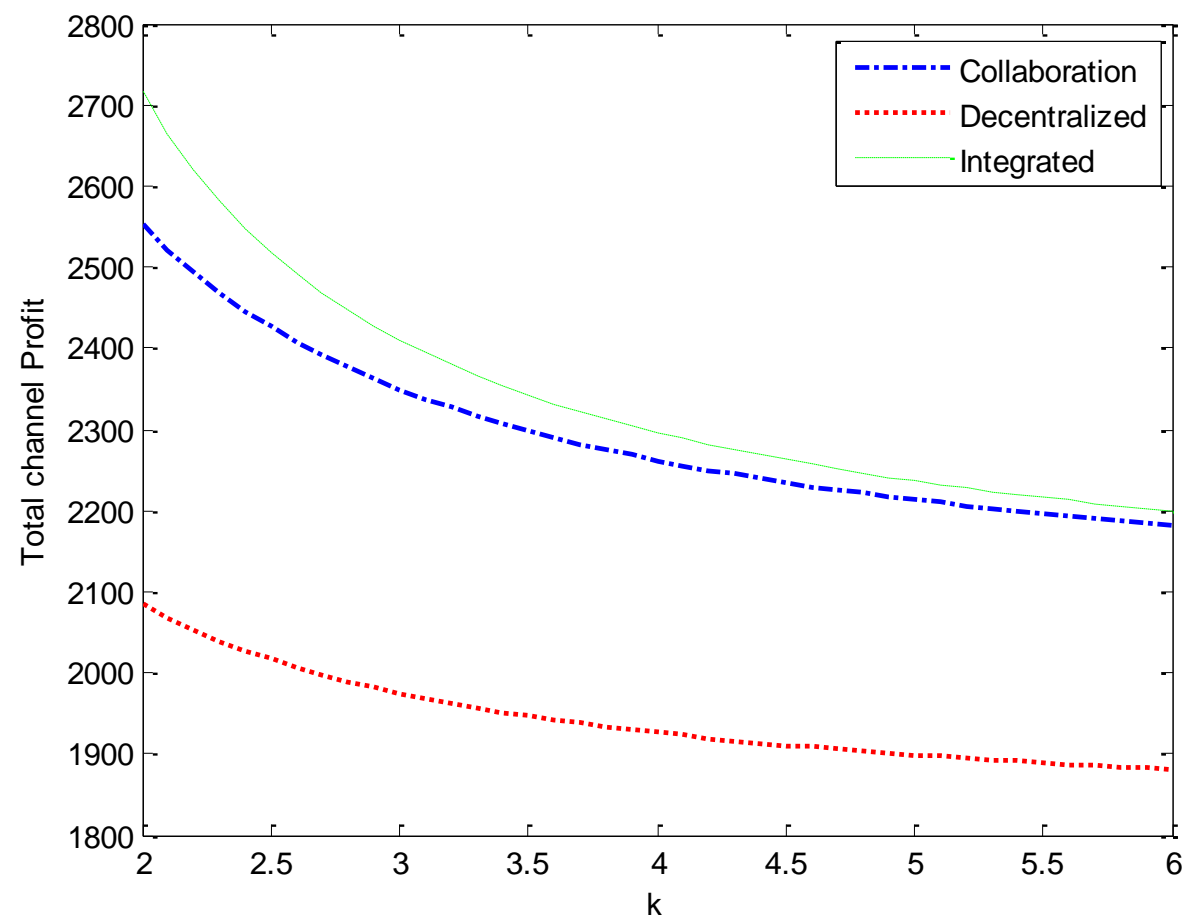

Figure 12. The effect of sales effort cost $k$ on the total channel profit.

\subsubsection{Impact of CEA level}

Consumer environmental awareness is a critical factor that can affect the demand of both green and non-green products. We analyze the impact of CEA on decisions made by the retailer and manufacturer. As CEA is a factor depending on the consumers' behavior and can vary from one community to another, we let the CEA to vary between relatively low to high values and observe the decisions made by both SC members under decentralized, integrated, and collaboration scenarios.

Figure 13 illustrates the equilibrium amount of environmental quality (the manufacturer's decision variable) under all three scenarios. For all levels of CEA, the collaboration scenario results in higher environmental quality than the decentralized scenario. It means that the collaboration scenario creates a greener channel than the decentralized scenario for all CEA levels. In addition, according to Figure 13, increasing CEA causes an increase in the manufacturer's decision variable in all three scenarios. The reason is intuitive; increasing CEA means more concerns of consumers regarding environmental issues and therefore, the tendency of consumers to buy greener product increases; thus, to satisfy the environmentally aware consumers, the manufacturer enhances environmental quality of products. 


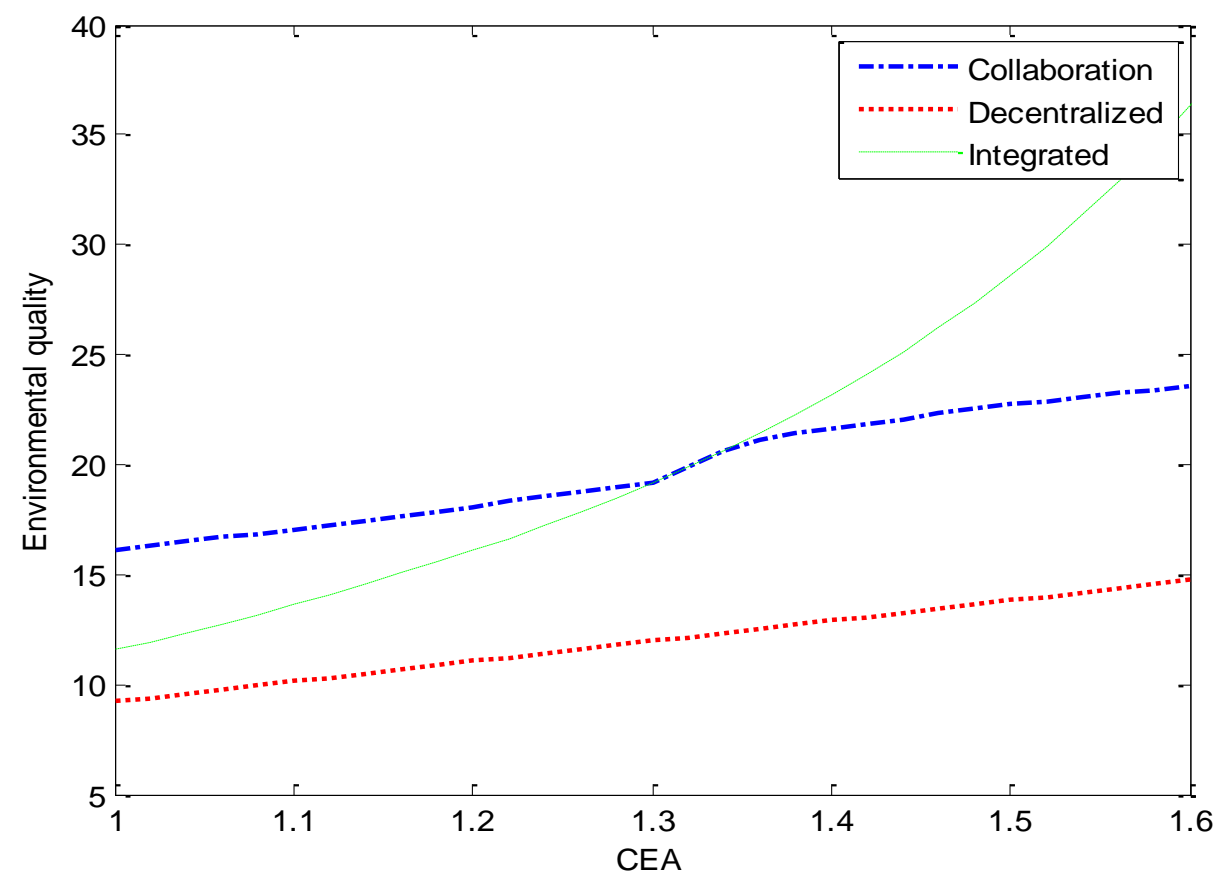

Figure 13. The effect of $\tau$ on the manufacturer's decision variable $e_{1}$.

On the other hand, increasing CEA influences the retailer's decisions on $p_{1}$ and $s_{1}$. According to Figures 14 and 15, by increasing $\tau$, the retailer sets both $p_{1}$ and $s_{1}$ in higher values in all the three scenarios. Increasing $p_{1}$ is a direct result of increasing $e_{1}$; indeed, by increasing $\tau$ the manufacturer produces a green product with higher quality (see Figure 13), as a result, the equilibrium price of the green product will be increased (see Figure 14). In total, increasing CEA causes the customers to receive greener product with higher prices. At the same time, the retailer makes more effort to sell the green product (see Figure 15). Comparing the decentralized scenario, the proposed collaboration model advises for more environmental quality and at the same time less prices along with more sales effort for all various CEA levels. This means more satisfied customers in result of adopting the proposed collaboration model in the investigated supply chain. 


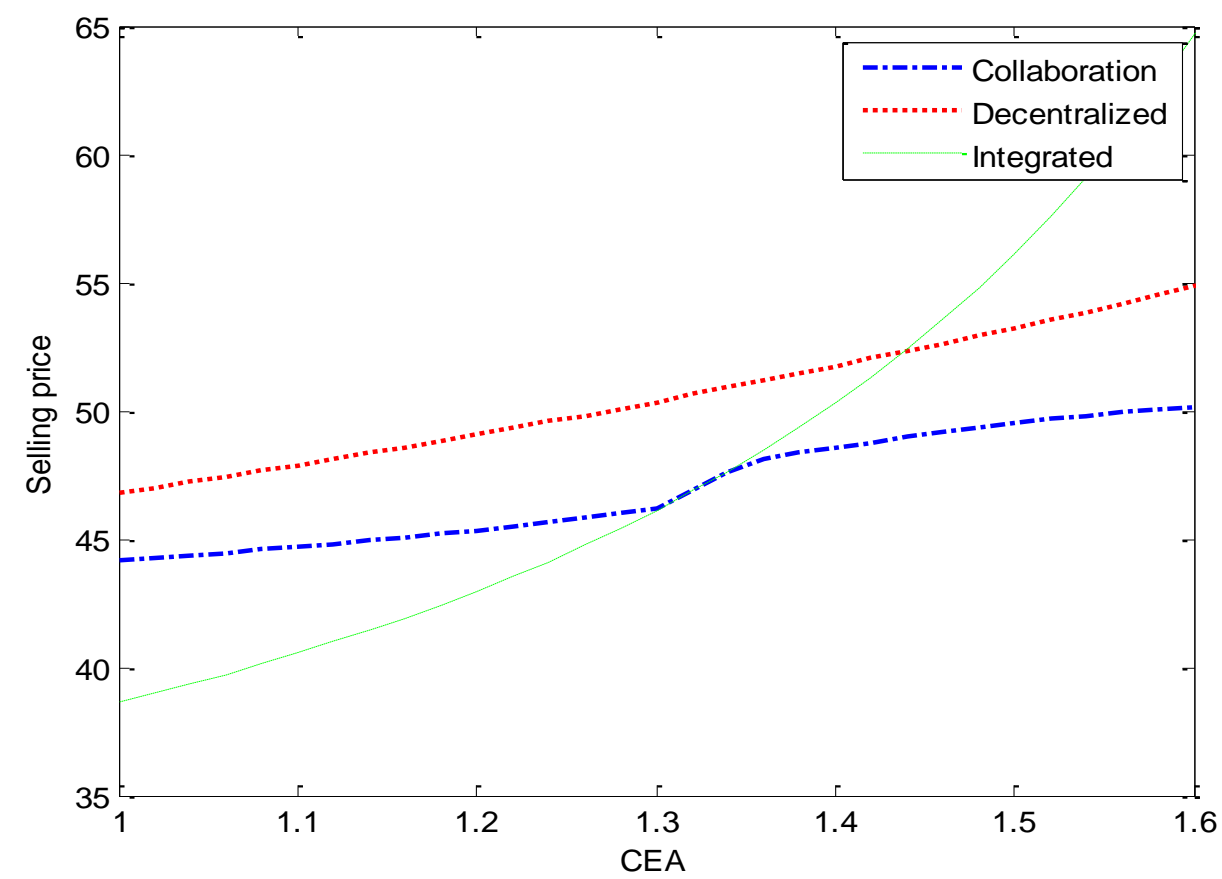

Figure 14. The effect of $\tau$ on the retailer's decision variable $p_{1}$.

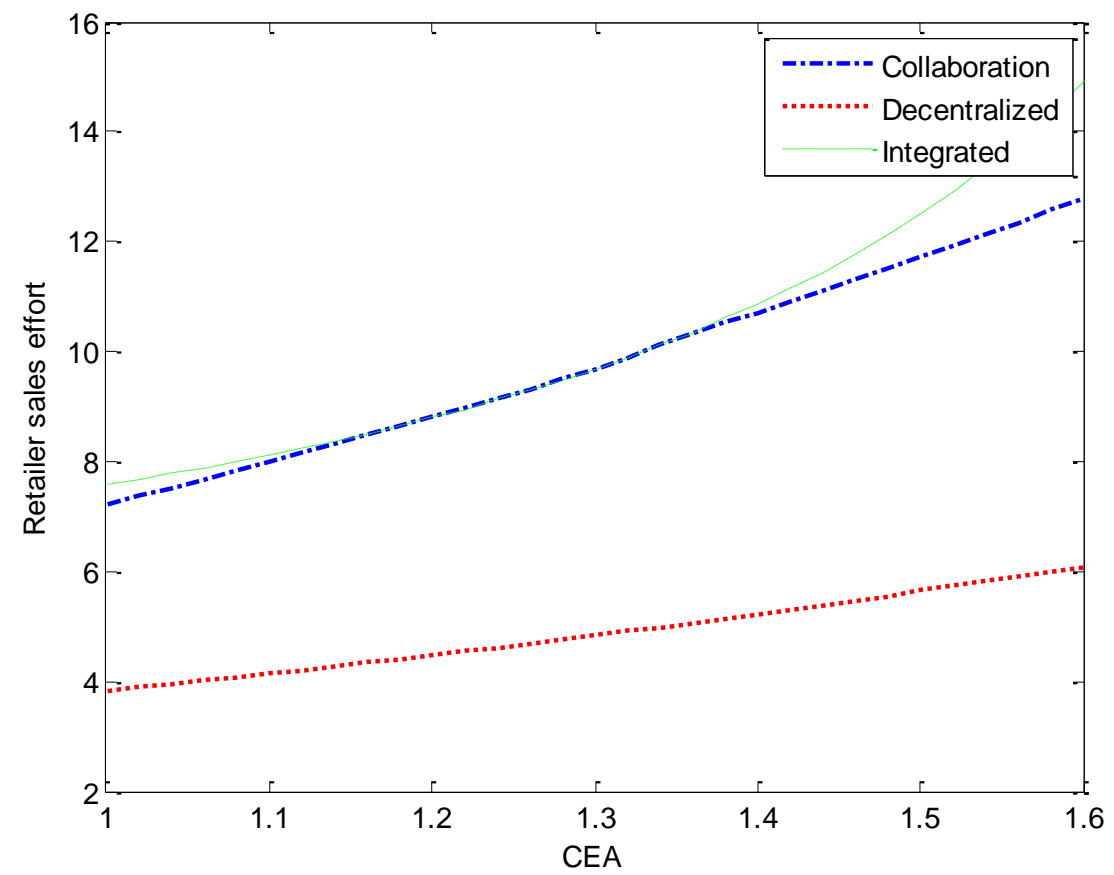

Figure 15. The effect of $\tau$ on the retailer's decision variable $s_{1}$. 


\subsubsection{Impact of sales-effort elasticity}

Sales effort elasticity $\gamma$ is an effective factor on the demand of green product. Since in our model we have $s_{2}=0$, the sales effort elasticity has no impact on demand of nongreen product. Figures 16 and 17 tracks the behavior of the retailer's decisions by increasing $\gamma$. By increasing $\gamma$, the retailer increases retail price $p_{1}$ to make more money per item sold and at the same time by increasing sales effort $s_{1}$ neutralizes the negative impact of high retail price on demand. In this way, the retailer not only takes advantage of increased sales volume, but also makes more profit per item sold. Meanwhile, comparing decentralized and collaboration scenarios in Figures 16 and 17 reveal that the proposed collaboration model sets fewer retail price and at the same time the retailer under the collaboration scenario makes more effort. This means that the retailer's activities and decisions under the collaboration decision making create more demand for the green product than the decentralized scenario. According to Figure 16, when $\gamma$ approaches $b$ and the sensitivity of customers to price and sales efforts are the same, the retail price under collaboration scenario approaches the retail price of decentralized scenario. However, it is worth mentioning that, in the real business environment, the customers are usually more sensitive to price and less to sales effort and therefore, it is expected that the proposed collaboration model advises for less retail price than the decentralized scenario in the real business cases.

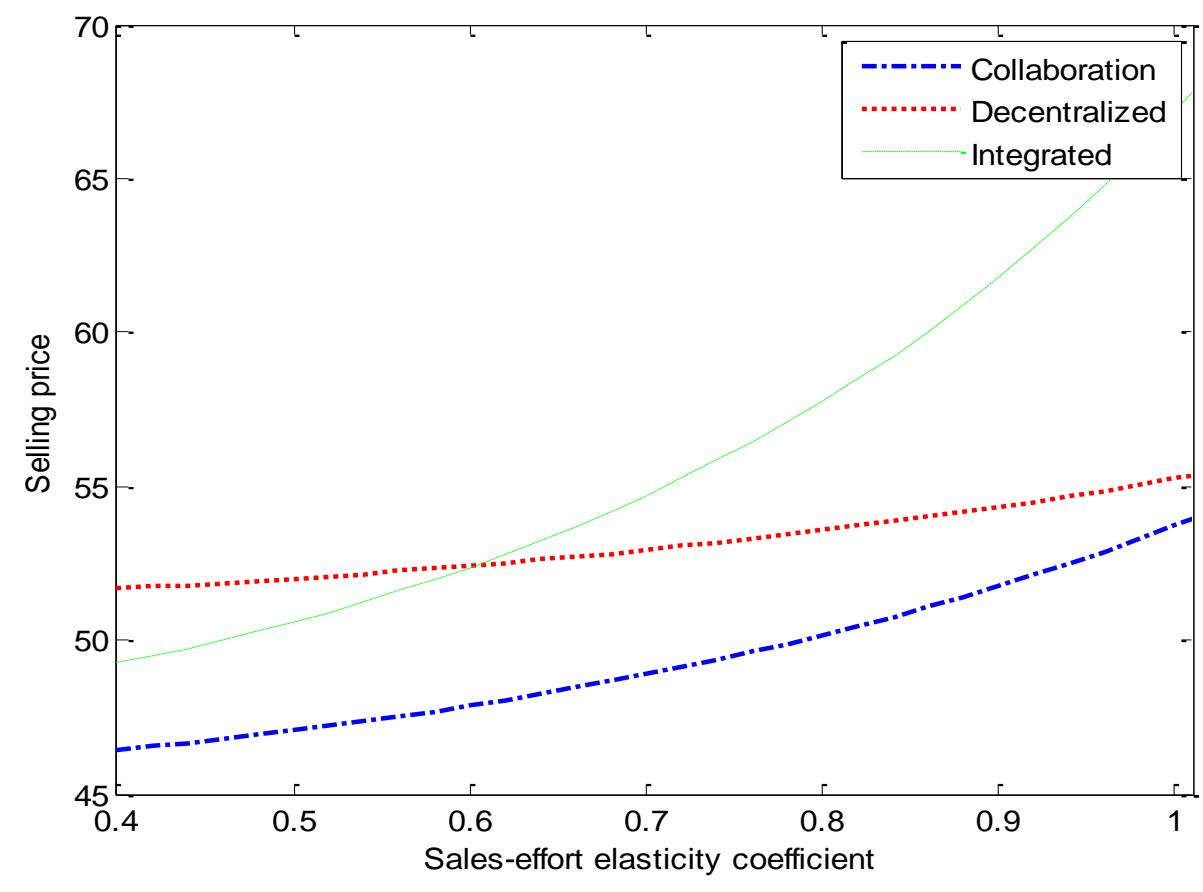

Figure 16. The effect of $\gamma$ on the retailer's decision variable $p_{1}$. 


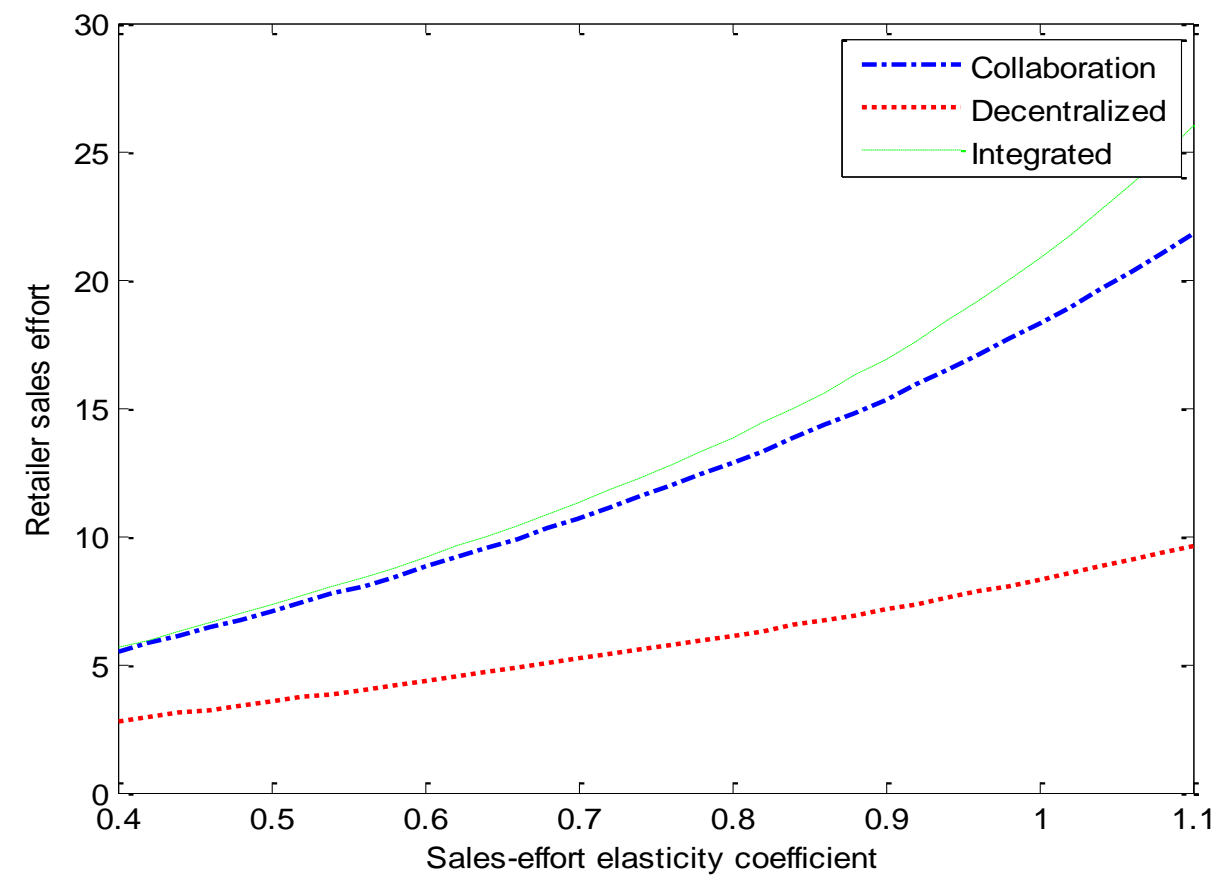

Figure 17. The effect of $\gamma$ on the retailer's decision variable $s_{1}$.

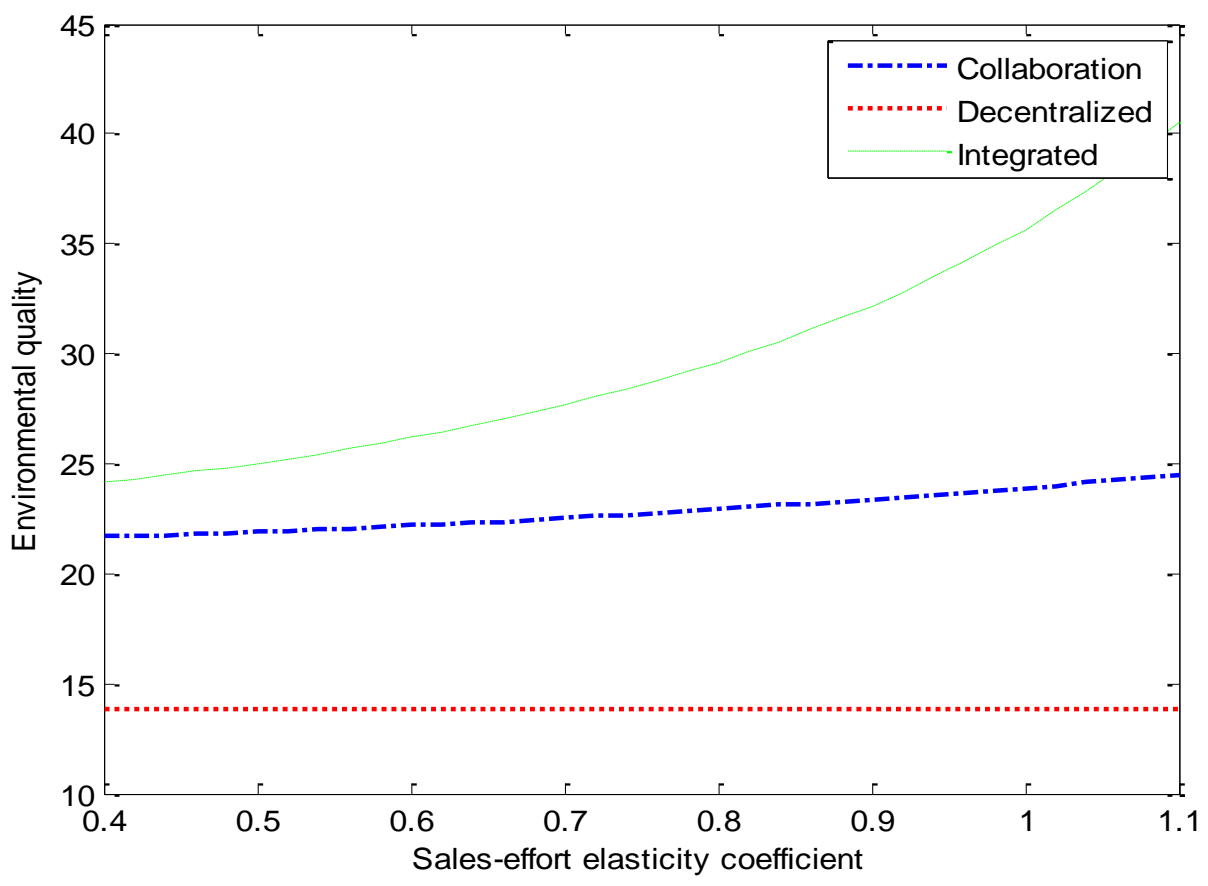

Figure 18. The effect of $\gamma$ on the manufacturer's decision variable $e_{1}$. 
Although changes in sales effort elasticity coefficient have a great impact on the retailer's decision making, it has a negligible impact on the manufacturer's decision. As it can be seen from Figure 18, under the collaboration scenario, by increasing $\gamma$ the manufacturer's decision $e_{1}$ changes negligibly. Indeed, it is expected that $\gamma$ affects the manufacturer's decision mediated by the retailer's decisions; however, the retailer's decisions $p_{1}$ and $s_{1}$ neutralize each other on the manufacturer's decision, and therefore, the manufacturer's decision does not influence.

\section{Conclusion and future works}

By rising environmental concerns among consumers all over the world, offering new green products to the customers becomes a competitive advantage for supply chains. As a result, in modern supply chains, the managers plan to introduce green products beside the non-green well-known products to attract the attentions of environmentally aware consumers.

In this study, at first stage, an analytical model of a two-stage (one manufacturer- one retailer) SC is developed. The investigated SC currently offers a traditional non-green product to the market and plans for launching a substitutable green product. Demand of both types of products is a definite function of retail price, product's environmental quality, and green sales effort. The non-green product is a well-known product with a given price and fixed environmental quality. The problem is deciding about retail price, environmental quality level, and sales effort for the new-introduced green product. The manufacturer decides about green quality of the product while the retailer has the full authority on retail price and green sales effort level.

Three different scenarios are investigated: (1) decentralized decision making, (2) Integrated scenario, (3) collaboration model. Our investigations revealed that the proposed collaboration model is capable of achieving solutions fairly close to the integrated scenario. The realized solution is Pareto-efficient in which no member is worse off with respect to the decentralized decision-making model. Closed-form relations for all decision variables are extracted, and also the collaboration model is developed as a mathematical programming model. All models are evaluated using numerical experiments. Our numerical investigations revealed that the proposed collaboration model stimulates demand and creates more profit for both members by appropriate adjustment of three decision variables; i.e. retail price, green sales effort level, and green quality of product. All test problems confirm that adoption of the proposed collaboration model creates a greener channel and at the same time reduces the retail price. Therefore, one can conclude that establishment of the proposed collaboration model results in more satisfied customers as well as more sustainable operations at the same time.

Managerial insights from the proposed model can be summarized as: (1) Offering a green type of product beside the non-green original type can lead to a synergic situation 
where both members take advantage of more sales volume and more profit, (2) collaboration in launching both product types leads to a more competitive prices and at the same time increases channel greenness, (3) Although the bargaining power of SC members can affect their shares, it cannot dampen the collaboration model, (4) The proposed collaboration model does not need for applying a side payment program and can create a win-win situation for both members.

For future research, we suggest investigating the green coordination issue under information asymmetry, where, the manufacturer is unaware of the cost parameters of the retailer and/or the retailer does not know the costs of enhancing green quality. Considering the problem under multiple sources of uncertainties is another opportunity for future researches.

\section{Acknowledgements}

We sincerely thank the Editor and three anonymous reviewers for their kind and helpful comments on this paper. This work was supported by the Iran National Science Foundation (INSF).

\section{References}

Chen, C. (2001). Design for the environment: A quality-based model for green product development. Management Science, 47, 250-263.

Chen, T.B., \& Chai L.T., (2010). Attitude towards environment and green products: Consumers perspective. Management Science and Engineering, 4 (2), 27-39.

Conrad, K., (2005). Price competition and product differentiation when consumers care for the environment. Environmental \& Resource Economics, 31, 1-19.

De Giovanni, P. (2011) Quality improvement vs. advertising support: Which strategy works better for a manufacturer?. European Journal of Operational Research, 208, 119-130.

De Giovanni, P. (2014). Environmental collaboration in a closed-loop supply chain with a reverse revenue sharing contract. Annals of Operations Research, 220, 135-157.

Du, F., Tang, w. and Song, M., (2016). Low carbon production with low carbon premium in cap and trade regulation. Journal of Cleaner Production, 1-11.

Gao, J., Han, H. and Wang, H., (2016), Pricing and effort decisions in a closed-loop supply chain under different channel power structures. Journal of Cleaner Production, 112, 2043-2057.

Ishaswini and Datta (2011). Pro-environmental Concern Influencing Green Buying: A Study on Indian Consumers. International Journal of Business and Management, 6(6). 124-133.

Ghosh, D. and Shah, J., (2012). A comparative analysis of greening policies across supply chain structures. International Journal of Production Economics, 135, 568-583.

Ghosh, D. and Shah, J. (2015). Supply chain analysis under green sensitive consumer demand and cost sharing contract. International Journal of Production Economics, 164, 319-329.

Govindan, K., Azevedo, S. G., Carvalho, H., \& Cruz-Machado, V. (2014a). Impact of supply chain management practices on sustainability. Journal of Cleaner Production, 85, 212-225. 
Govindan, K., Kaliyan, M., Kannan, D., \& Haq, A. N. (2014b). Barriers analysis for green supply chain management implementation in Indian industries using analytic hierarchy process. International Journal of Production Economics, 147, 555-568.

Gupta, S. and Palsule-Desai, O.D. (2011). Sustainable supply chain management: Review and research opportunities. IIMB Management Review, 23, 234-245.

Heydari, J., \& Norouzinasab, Y. (2015). A two-level discount model for coordinating a decentralized supply chain considering stochastic price-sensitive demand. Journal of Industrial Engineering International, 11(4), 531-542.

Heytko, D. L. and Matulich, L., (2008). Green advertising and environmentally responsible consumer behaviors: Linkages examined. Journal of Management and Marketing Research, 1, 2-11.

Hsieh, C. C., \& Wu, C. H. (2009). Coordinated decisions for substitutable products in a common retailer supply chain. European Journal of Operational Research, 196(1), 273-288.

Jaber, M. Y. Glock, C. \& M.A. El Saadany, A. (2013). Supply chain coordination with emissions reduction incentives. European Journal of Operational Research, 51, 69-82.

Krommyda, I. P., Skouri, K., \& Konstantaras, I. (2015). Optimal ordering quantities for substitutable products with stock-dependent demand. Applied Mathematical Modelling, 39(1), 147-164.

Kumar, S., Teichman, S. and Timpernagel, T. (2012). A green supply chain is a requirement for profitability. International Journal of Production Research, 50(5), 1278-1296.

Lau, H. SH., Su, ch., Wang, Y. Y. and Hua, Zh. Sh. (2012). Volume discounting coordinates a supply chain effectively when demand is sensitive to both price and sales effort. International Journal of Production Economics, 144, 572-581.

Li, B., Zhu, M., Jiang, Y. and Li, Zh. (2016). Pricing policies of a competitive dual channel supply chain. Journal of Cleaner Production, 112(3), 2029-2042.

Li, J., \& Liu, L. (2006). Supply chain coordination with quantity discount policy. International Journal of Production Economics, 101(1), 89-98.

Liu, Z., Anderson, T.D. and Cruz, J.M., (2012). Consumer environmental awareness and competition in two-stage supply chains. European Journal of Operational Research, 218, 602-613.

Ma, P., Wang, H. and Shang, J., (2013a). Contract design for two-stage supply chain coordination: Integrating manufacturer-quality and retailer-marketing efforts. Int. J. Production Economics, 146, 745-755.

Ma, P., Wang, H. and Shang, J., (2013b). Supply chain channel strategies with quality and marketing effort-dependent demand. Int. J. Production Economics, 144, 572-581.

Ramanathan , U., Bentley, Y. and Pang, G., (2014).The role of collaboration in the UK green supply chains: an exploratory study of the perspectives of suppliers, logistics and retailers. Journal of Cleaner Production, 70, 231-241.

Ramlogan, R. (1997). Environment and human to all. Environmental Management and Health, 8, 5166.

Saha, S., \& Goyal, S. K. (2015). Supply chain coordination contracts with inventory level and retail price dependent demand. International Journal of Production Economics, 161, 140-152.

Teisl, M.F., Roe, B., Hicks, R.L., (2002). Can eco-labels tune a market? Evidence from dolphin-safe labeling. J. Environ. Econ. Manag, 43 (3), 339-359.

Tsay, A.A. and Agrawal, N. (2000). Channel dynamics under price and service competition. Manufacturing \& Service Operations Management, 2(4), 372-391. 
Wang, C., Huang, R., \& Wei, Q. (2015). Integrated pricing and lot-sizing decision in a two-echelon supply chain with a finite production rate. International Journal of Production Economics, 161, 44-53.

Wu, D. D., (2013). Bargaining in supply chain with price and promotional effort dependent demand. Mathematical and Computer Modelling, 58, 1659-1669.

Xia, L. and He, L. (2014). Game theoretic analysis of carbon emission reduction and sales promotion in dyadic supply chain in presence of consumers' low-carbon awareness. Discrete Dynamics in Nature and Society, 2014, Article ID 837376, 1-13.

Zhang, C. T. and Liu, L. P. (2013). Research on coordination mechanism in three-level green supply chain under non-cooperative game. Applied Mathematical Modelling, 37(5), 3369-3379.

Zhang, C.T., Wang H.X. and Ren, M.L., (2014). Research on pricing and coordination strategy of green supply chain under hybrid production mode. Computers \& Industrial Engineering, 72, 2431.

Zhang, L. Wang, J. and You, J. (2015). Consumer environmental awareness and channel coordination with two substitutable products. European Journal of Operational Research, 241(1), 63-73.

Zhao, J., Tang, W., \& Wei, J. (2012a). Pricing decision for substitutable products with retail competition in a fuzzy environment. International Journal of Production Economics, 135(1), 144153.

Zhao, J., Tang, W., Zhao, R., \& Wei, J. (2012b). Pricing decisions for substitutable products with a common retailer in fuzzy environments. European Journal of Operational Research, 216(2), 409419.

Zhao, J. and Wei, J., (2014). The coordinating contracts for a fuzzy supply chain with effort and price dependent demand. Applied Mathematical Modelling, 38, 2476-2489.

Zhao, J., Wei, J., \& Li, Y. (2014). Pricing decisions for substitutable products in a two-echelon supply chain with firms' different channel powers. International Journal of Production Economics, 153, 243-252. 